\title{
Application of Superhydrophobic Coatings as a Corrosion Barrier: A Review
}

E. Vazirinasab*, R. Jafari, G. Momen

Department of Applied Sciences, University of Québec in Chicoutimi (UQAC)

555, boul. de l'université, Chicoutimi, Québec, G7H 2B1 Canada

* E-mail: elham.vazirinasab1@uqac.ca

\begin{abstract}
This review provides an overview of recent advances in the application of superhydrophobic surfaces to act as corrosion barriers. The adverse consequences of corrosion are a serious and widespread problem resulting in industrial plant shutdowns, waste of valuable resources, reduction in efficiency, loss or contamination of products, and damage to the environment. Superhydrophobic surfaces, inspired by nature, can be considered as an alternative means for improving the protection of metals against corrosion. Due to the possibility of minimizing the contact area between liquids and a surface, superhydrophobic surfaces can offer great resistance to corrosion. Artificial superhydrophobic surfaces have been developed with the potential of being applied in numerous settings including self-cleaning, anti-icing, oil-water separation, and especially anti-corrosion applications. In this paper, we review the concept of superhydrophobicity through presentation of different theoretical models. The fabrication and application of superhydrophobic surfaces are presented and we then discuss the use of superhydrophobic coatings as barriers against the corrosion of metals.
\end{abstract}

Keywords: Corrosion resistance, superhydrophobic, contact angle, metal.

\section{Introduction}


Metals and their alloys are engineered materials that are central to numerous industrial fields. Aluminum $(\mathrm{Al})$, copper $(\mathrm{Cu})$, magnesium $(\mathrm{Mg})$, steel, and their alloys are common metals used in a wide range of industrial, construction, marine, and aeronautical applications. Although many physical characteristics of metals, such as ductility, stiffness, and a high strength to weight ratio make these materials very useful, they do have limitations. Corrosion of metals in aggressive environments is one of these [1]. The corrosion of metals can produce a premature failure of metallic components, resulting in financial losses, environmental contamination, and injury or death $[2,3]$. Corrosion is one of the main causes of energy and material loss, accounting for $20 \%$ of global energy use. An average of $4.2 \%$ of the gross national product (GNP) is lost each year because of corrosion-related issues [4]. The majority of this cost is allocated to the examination of corroded parts of the structures, the repair of the structures using various methods including protective coatings (paints, surface treatments, etc.), and discarding the potentially hazardous waste materials [5].

There are different techniques for preventing the corrosion of metals. One is the coating of a metal surface with an anti-corrosive layer to provide a barrier between the metal surface and the corrosive environment [6-8]. However, contact between the corrosive solution and the metal/coating interface will corrode the metal surface $[9,10]$. Therefore, reduced interfacial tension or an increased water proofing of the surface can be a more effective protective coating. Use of good quality corrosion resistant coatings on heavy structures, e.g., bridges and industrial sheds, can help prevent the weakening and collapse of these constructions [3].

Inspired by a vast number of natural phenomena, such as the self-cleaning characteristics of the lotus leaf and the "anti-water" legs of a water strider, artificial superhydrophobic surfaces have been developed [11-15]. Superhydrophobic surfaces with a water contact angle (WCA) greater 
than $150^{\circ}$ and a water sliding angle (SA) or contact angle hysteresis (CAH) of less than $10^{\circ}$ have attracted tremendous attention due to their broad applications in scientific and industrial applications, such as self-cleaning [16-20], anti-fouling [21-23], anti-icing [7, 24, 25] cases, as well as for oil-water separation [26, 27], and drag reduction [28, 29]. Superhydrophobic coatings have been successfully developed as corrosion protection for many metals and their alloys surfaces, including aluminum [12, 30, 31], copper [32-34], magnesium [35-37], and steel [38, 39]. In this review, we first provide a brief introduction to natural superhydrophobic surfaces and present the fundamental theories related to the wetting and non-wetting behavior of solid surfaces. Then, we discuss the numerous methods for fabricating superhydrophobic surfaces and diverse application of these coatings. Finally, we outline the use of superhydrophobic coatings as corrosion protection for aluminum, copper, magnesium, and steel, and present a brief conclusion.

\section{Superhydrophobicity}

Surface wettability is one of the most important properties of solid surfaces and plays a significant role in a wide range of practical applications in daily life, industry, and agriculture [12]. The WCA is defined as the angle where a liquid-vapor interface meets a solid surface. Hydrophilicity and hydrophobicity are the most common terms introduced to describe the relative affinity of water droplets on solid surfaces. As shown in Figure 1, if the WCA is smaller than $90^{\circ}$, the solid surface is defined as hydrophilic, and greater than $90^{\circ}$, the surface is considered as hydrophobic. On a hydrophilic surface, a water droplet wets as large a surface as possible, likely entering the pores of the material and completely saturating it. On the other hand, a water droplet is repelled by a hydrophobic surface and takes on a near spherical shape. Superhydrophilicity is characterized by a WCA less than $10^{\circ}$ that describes a complete spreading of water on the substrate. In contrast, superhydrophobicity, defined as a surface having a WCA larger than $150^{\circ}$, describes an almost 
non-wetting state [40]. Besides static contact angle considerations, $\mathrm{CAH}$ and SA are other important criteria for studying the surface behavior of various materials. The water SA is defined as the critical angle at which a water droplet of a certain weight begins a downward slide. CAH represents the difference between advancing and receding contact angles. Both are criteria of dynamic hydrophobicity. Generally, superhydrophobic surfaces are defined as any surface for which the static contact angle is more than $150^{\circ}$ and the SA or CAH is less than $10^{\circ}[41,42]$.

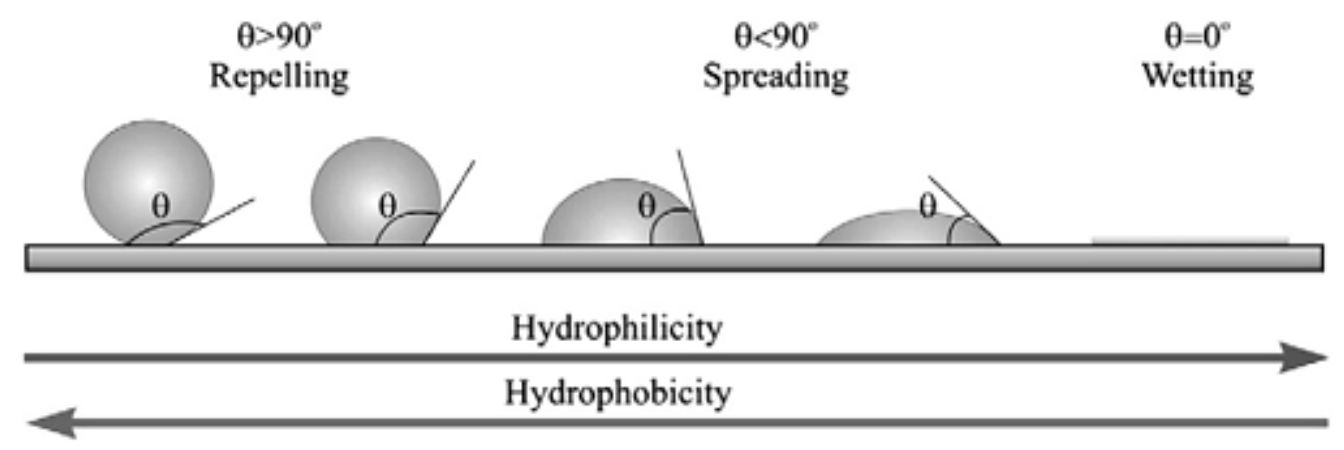

Figure 1: Schematic of the shape of a water drop and the water contact angle (WCA) for solid surfaces along a hydrophobicity-hydrophilicity gradient [43]

\subsection{Superhydrophobic surfaces in nature}

A wide variety of superhydrophobic surfaces can be found in nature. Excellent capacities for water repellency are demonstrated by many plants and animals including lotus leaves $[44,45]$, rose petals [46], taro leaves [44], rice leaves [47], water strider legs [48], cicada wings [49, 50], butterfly wings [51], body feathers of penguins [52], and numerous other examples [14, 46, 53, 54]. Lotus (Nelumbo nucifera) leaves are one of the most prominent instances among naturally occurring superhydrophobic surfaces. The rolling and bouncing of liquid droplets on the surface of lotus leaves removes contaminants and thus acts as a self-cleaning property [28]. This self-cleaning effect is due to a high WCA of $161 \pm 2^{\circ}$ and low SA of $2^{\circ}$. This effect has made this plant a symbol 
of purity $[19,44,49,55]$. Electron microscopy indicates that a combination of hierarchical surface roughness and low surface energy wax-like materials are the principal reasons for this superhydrophobicity. Its hierarchical rough structure is comprised of a two-level roughness of an initial micro-sized $(3-10 \mu \mathrm{m})$ roughness having protrusions and valleys covered by a second epicuticular waxy layer of hydrophobic crystalloids having nano-sized (70-100 nm) roughness [49, 56-58]. Water strider legs, rice, and taro leaves are other examples of hierarchical superhydrophobic structures $[48,58]$. In addition to this "lotus effect", there is a "petal effect" referencing the high contact angle of $152.4^{\circ}$ for rose petal surfaces on which a water droplet cannot roll or slide even when the surface is turned upside down. This demonstrates a distinct type of superhydrophobicity, one marked by high adhesion $[46,59]$. The micro- and nano-textures of the lotus leaf and rose petal are observed in Figure 2. The diversity of micro- and nano-structures on the surface of the lotus leaf and rose petals lead to differences in dynamic wetting. On the surface of the rose petal, there are cuticular nanofolds positioned on top of an array of hierarchical micropapillae having an average diameter of $16 \mu \mathrm{m}$ [46]. In addition to a hierarchical structure, some surfaces in nature benefit from a fibrous structure to obtain superhydrophobicity and selfcleaning properties [47, 60-62]. Silver ragwort leaves (Senecio cineraria), Chinese watermelon, the carnivorous plant Drosera burmanni and Ramee leaves are some examples of superhydrophobic fibrous leaves [47, 62]. For instance, silver ragwort leaves have closely compacted fibers, ca. $6 \mu \mathrm{m}$ in diameter, that cover the leaf surface and lead to superhydrophobic surfaces with a WCA of $147^{\circ}$ (Figure 2 (e) and (f)) [60, 61]. 

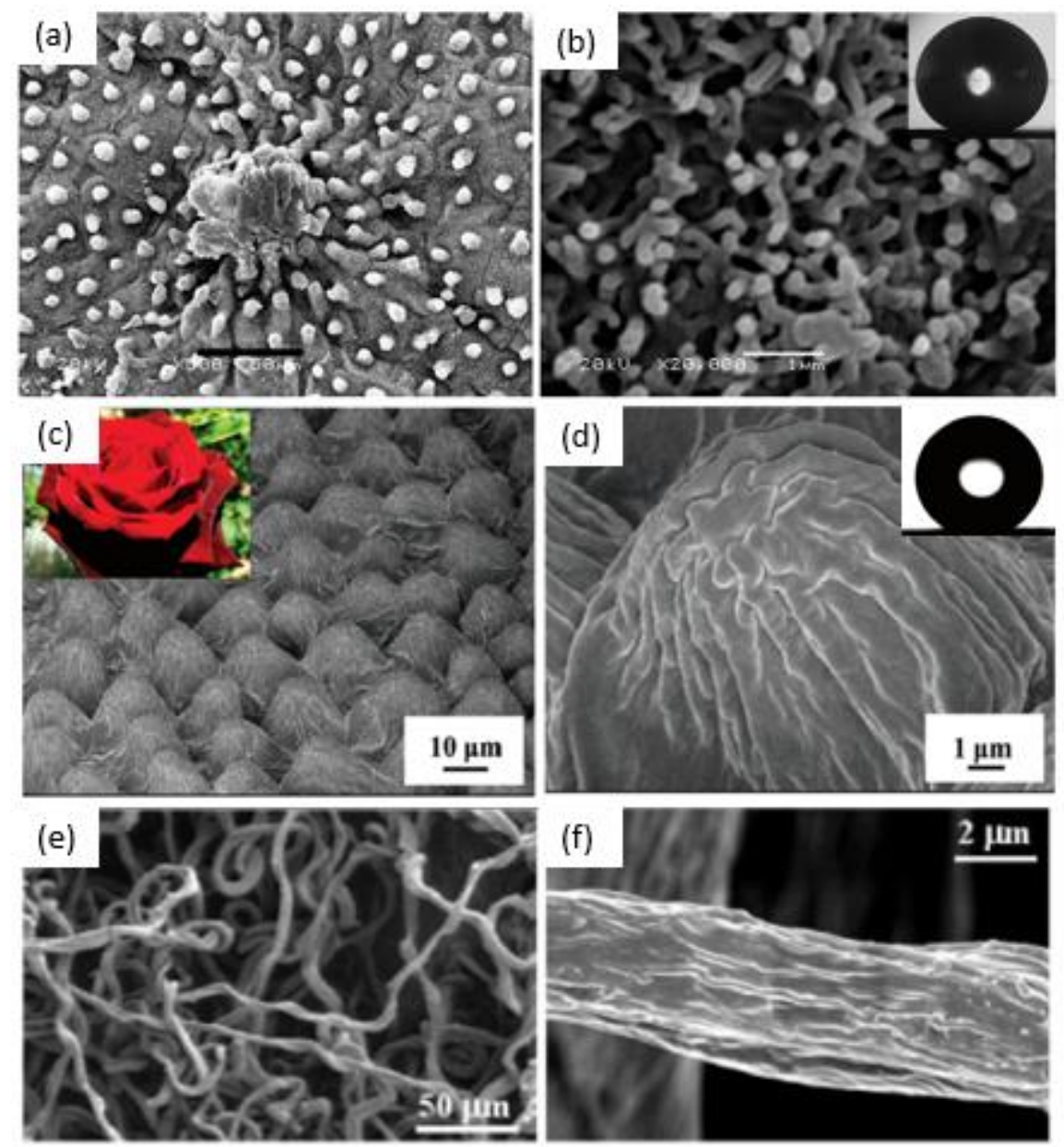

Figure 2: SEM images of superhydrophobic surfaces at low and high magnifications. (a) and (b) lotus leaf with a $162^{\circ}$ water contact angle; (c) and (d) rose petal with a $152.4^{\circ}$ water contact angle; (e) and (f) silver ragwort leaf with a $147^{\circ}$ water contact angle [46, 47, 61].

\subsection{Wettability and superhydrophobicity}

Over the last few decades, the wettability of solid surfaces and solid-liquid physical interactions have been intensely studied. Young, Wenzel, and Cassie-Baxter are the principal equations for explaining surface wettability. Young's equation is the starting point for wetting models that result from the equilibrium of interaction forces along the triple line. It determines the static contact angle of a sessile drop on an ideal smooth, homogenous, rigid, and insoluble solid surface (Figure 3 (a)). 
As shown in Eq. 1, according to the Young's equation, the static contact angle depends only on the thermodynamic equilibrium of the interfacial tension of the solid-liquid-vapor interfaces [63, 64]:

$$
\cos \theta=\frac{\gamma_{S V}-\gamma_{S L}}{\gamma_{L V}} \quad E q .1
$$

where $\theta$ is the contact angle, and $\gamma_{\mathrm{SV}}, \gamma_{\mathrm{SL}}$, and $\gamma_{\mathrm{LV}}$ are the interfacial tension of the solid-vapor, solid-liquid, and liquid-vapor interfaces respectively. It is clearly understood from Eq. 1 that forasmuch as the surface tension of water and its surroundings (usually air) are fixed, a decrease in the surface tension of a solid material leads to an increase in the static contact angle. Although the order of the surface energies of the chemical groups are known as $\mathrm{CH}_{2}>\mathrm{CH}_{3}>\mathrm{CF}_{2}>\mathrm{CH}_{2} \mathrm{~F}$ $>\mathrm{CF}_{3}$, the highest reached static contact angle of a smooth surface using $\mathrm{CF}_{3}$, as a chemical groups with lowest surface energy, is about $120^{\circ}$, which does not fulfill the requirement for superhydrophobicity $[65,66]$.

Surface roughness is, therefore, the second critical factor for obtaining a superhydrophobic surface. Higher surface roughness, combined with a lower surface energy are required to achieve a superior contact angle and superhydrophobicity. Many researchers, in particular Wenzel and Cassie-Baxter, endeavored to formulate a relationship between surface tension, roughness, and contact angle [67]. Based on Wenzel's studies of the wettability of porous surfaces, the roughness of a surface dramatically affects the contact angle on the surface. As shown in Figure 3(b), the liquid penetration into the rough grooves and the increase in the interfacial area for the spreading liquid are the main assumptions in Wenzel's theory $[68,69]$. At thermodynamic equilibrium, Wenzel's homogeneous wetting state proposed a linear relationship between the apparent contact angle and the roughness factor of the surface [70]: 


$$
\cos \theta_{W}=\frac{r\left(\gamma_{S V}-\gamma_{S L}\right)}{\gamma_{L V}}=r \cos \theta \quad E q .2
$$

where $\theta_{\mathrm{w}}$ is the apparent contact angle on the rough surface, $\theta$ is Young's contact angle on a similar smooth surface, and $\mathrm{r}$ is the surface roughness factor. The surface roughness factor is defined as the ratio between the actual surface area and the geometrical projected surface area. Therefore, for a rough surface, $\mathrm{r}$ is $>1$. According to Wenzel's equation, creating roughness increases both the hydrophobicity and hydrophilicity, taking into consideration the prior nature of the surface. Thus, if the contact angle of the surface is $>90^{\circ}$, hydrophobicity is improved by roughness whereas if the contact angle is $<90^{\circ}$, hydrophilicity is enhanced[71].

Young and Wenzel's theory, known as the homogeneous wetting state, occurs when a drop of liquid fills up the roughness grooves. A heterogeneous wetting state like Cassie-Baxter has air (or another fluids) trapped in the roughness grooves underneath the liquid and thus the liquid is prevented from penetrating into the pores (Figure 3 (c)) [72]. In practical terms, the Cassie-Baxter equation applies only when the liquid is in contact with the solid surface at the top of the protrusions (Eq. 3) [56, 73, 74]:

$$
\cos \theta_{C B}=f_{s} \cos \theta-\left(1-f_{s}\right)=f_{s} \cos \theta+f_{s}-1 \quad \text { Eq. } 3
$$

where $\theta_{\mathrm{CB}}, \theta$, and $\mathrm{f}_{\mathrm{s}}$ are the Cassie-Baxter contact angle, the Young's contact angle, and the ratio between the total area of solid-liquid interface and the total area of solid-liquid and liquid-air interface of the projected area, respectively. In addition, by the inclusion of the roughness factor of the wetted surface area, $\mathrm{r}_{\mathrm{f}}$, the Cassie-Baxter equation will be modified to this equation (Eq. 4) $[56,75]:$

$$
\cos \theta_{C B}=r_{f} f_{s} \cos \theta+f_{s}-1 \quad E q .4
$$

Where $f_{s}=1$ and $r_{f}=r$, the Cassie-Baxter equation converts to the Wenzel equation. According to the Cassie-Baxter model, an increase in surface roughness leads to an increase in the amount of 
air trapped in the grooves. Consequently $\mathrm{f}_{\mathrm{s}}$ decreases and the contact angle increases [67]. These theories explain the impact of surface roughness on the static contact angle and how hydrophobicity and hydrophilicity may be enhanced. Due to the great mobility of droplets on surfaces having an ultra-high roughness, the dynamic of the droplet on the surface must be taken into consideration $[70,76]$.

(a)

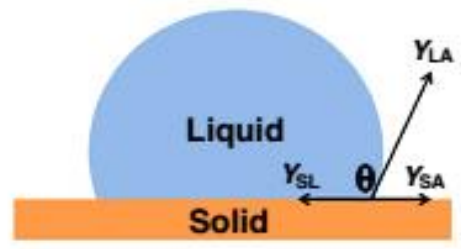

(b)

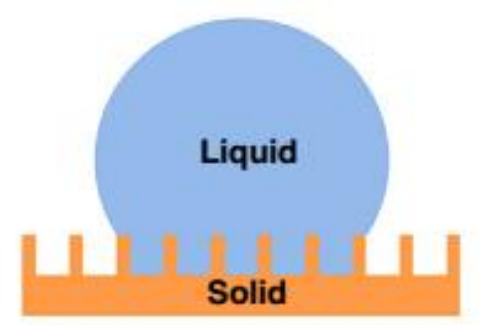

(c) Cassie

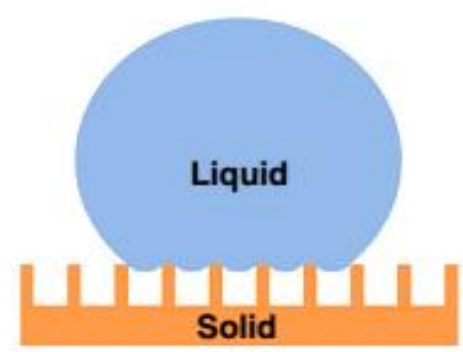

Figure 3: A liquid droplet on different surfaces: (a) Young's model; (b) Wenzel's model; (c) the Cassie-Baxter model [77].

The ability of a surface to shed water is defined as dynamic hydrophobicity. The molecular interactions between the liquid and the solid surface or irregularities, such as roughness or heterogeneities, can lead to hysteresis [40, 67, 78, 79]. Wenzel's and Cassie-Baxter's models are the dominant regimes in small and high roughness situations, respectively. Surfaces of the Wenzel model demonstrate high static and advancing contact angles but low receding contact angles. This leads to the high hysteresis and stiction of the water droplets to the surface. Highly mobile drops having a high contact angle and low hysteresis on superhydrophobic surfaces are in accordance with the Cassie-Baxter state [76, 80]. 


\subsection{Fabrication of superhydrophobic surfaces}

As previously discussed, surface chemical composition and surface roughness are the key factors contributing in the formation of superhydrophobic surfaces. Over the recent decades, researchers have fabricated superhydrophobic surfaces mainly by the combination of: (i) roughening the surface of low surface energy material or (ii) modifying a rough surface by depositing low surface energy materials $[81,82]$. In the first approach, numerous methods are employed to create roughness on low surface energy materials or inherently hydrophobic surfaces, such as silicones, fluorocarbons, and long chain fatty acids [83]. The second approach is applied where it is not possible to use hydrophobic materials. For hydrophilic materials, creating surface roughness should be performed prior to the surface modification by a low surface energy material. Long alkyl chain thiols, alkyl or fluorinated organic silanes, perfluorinated alkyl agents, long alkyl chain fatty acids, PDMS-based polymers, or their combinations are the main reactive molecules used for low surface energy modification [84]. There are many methods and techniques to create roughness followed by modification to achieve superhydrophobic surfaces, such as templating [85, 86], etching [87-89], hydrothermal synthesis [90-92], anodization [93-97], electrodeposition [34, 98100], sol-gel [33, 37, 101], nanocomposite coating [102-105], and spray coating [106-108]. We provide a brief description of some of these important techniques in the following subsections.

\subsubsection{Templating}

Template-based methods prepare superhydrophobic surfaces using an intermediate surface termed as master template. Master templates can be divided into two major groups: polymers and metals. Natural surfaces, such as leaves, insect wings, and reptile skins, are typically used as prototypes to produce polymeric master templates [55, 109-111]. The desired micro- and nano-scale surface roughness of the metals master templates can be created through other methods, such as etching 
[112]. The templating process includes the use of a master template having the desired specifications, then molding to replicate these specifications. Templates are subsequently removed by either lifting the replica off the template or by dissolving the templates. This is a widely used method for preparing polymeric surfaces due to it being a low cost, rapid, and repeatable procedure. The main advantage of this method is that natural surfaces can be replicated. Peng et al. [113] prepared a PDMS master template by casting the liquid PDMS directly onto a natural, fresh Xanthosoma sagittifolium leaf and curing it at $50{ }^{\circ} \mathrm{C}$ for $4 \mathrm{hr}$, then removing the hardened PDMS template (Figure 4). Subsequently, this master template was used for preparation of a replica composed of polyaniline on cold rolled steel. The superhydrophobic polyaniline film had almost the identical micro- and nano-scale surface morphology as the natural Xanthosoma leaf.

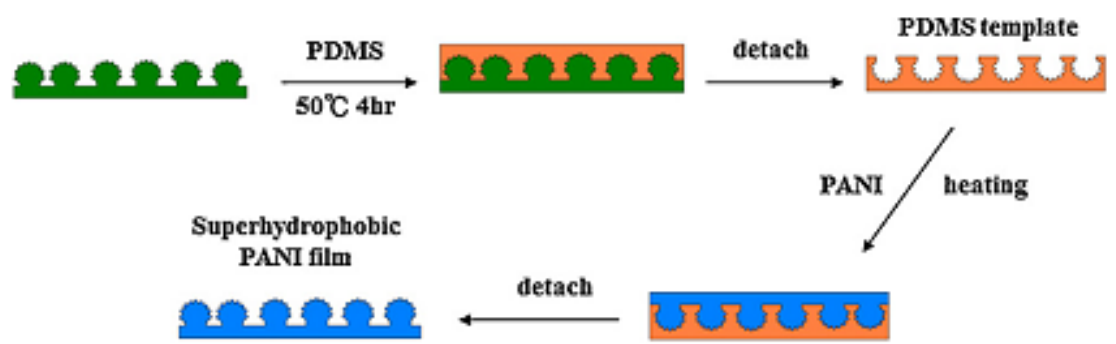

Figure 4: The preparation scheme of the superhydrophobic polyaniline (PANI) film through the templating replication process [113].

\subsubsection{Etching}

A surface roughening method by simple etching was developed for the fabrication of superhydrophobic surfaces for various materials [114]. Different relative etching rates of crystal planes and/or that of matrix in comparison to crystalline areas is the reason for the increase in the surface roughness. Depending on the method used, the surface roughness falls in the crystallitesize range or smaller. After the surface roughness is created, a low surface energy material is then grafted to the surface to acquire superhydrophobicity [115]. Etching can be divided into two main 
categories: i) dry etching, such as plasma and reactive ion etching $[25,67,93,116]$ in which generation of reactive atoms or ions in a gas discharge leads to the anisotropic etching of the surface, and ii) wet chemical etching [88, 117, 118] using acid or base solutions that etch dislocations or impurities on metal substrates by acid or base solutions. Immersion in chemical etchants destroys many of the high energy dislocation sites that exist in crystalline metals. The destruction of these sites leads to the formation of micro- and nano-scale surface roughness [119]. There are advantages and disadvantages for the chemical etching method. Chemical etching is an inexpensive and relatively simple approach that can be easily scaled-up. However, due to the use of various corrosive acids, such as sulfuric, oxalic, and phosphoric acids, this method is hazardous and is not an environmentally friendly procedure $[12,120]$.

\subsubsection{Hydrothermal synthesis}

Hydrothermal synthesis is a versatile method for the fabrication of micro- and nano-scale materials, such as powdered nanomaterials, that have novel and interesting morphologies [121, 122]. The hydrothermal method synthesizes the micro- and nano-structures of the surface using an aqueous media under raised heat and/or pressure. As the main chemical materials are $\mathrm{H}_{2} \mathrm{O}$ or dilute $\mathrm{H}_{2} \mathrm{O}_{2}$, this method is considered as being environmentally friendly [123, 124]. Jun Cho et al. [90] achieved a superhydrophobic surface through use of the hydrothermal method to create cerium oxide nanorod-shaped nano-structures on diverse substrates. The diverse substrates were placed in a growth solution of cerium nitrate hexahydrate and urea with deionized water and then heated up to $95{ }^{\circ} \mathrm{C}$ for 24 h to create superhydrophobic surfaces (Figure 5).

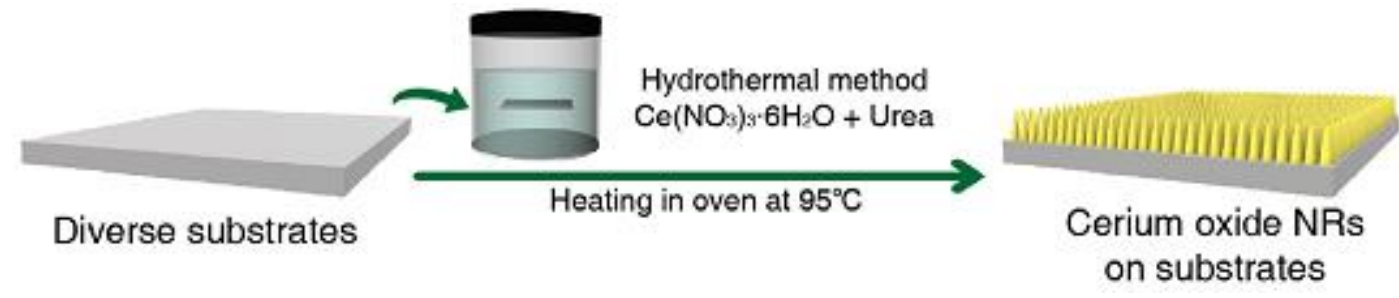


Figure 5: Preparation scheme using the hydrothermal method to create cerium oxide nanorods [90].

\subsubsection{Anodization}

The anodization method is one of the well-established approaches for generating micro- and nanoscale roughness with an oxide layer at the surface of metals through use of an electrochemical cell. In this technique, the reaction between metal ions and water in the presence of protons leads to metal oxidation. This method has the advantages of low cost, easy and rapid fabrication, easy scale-up, and precise control of surface roughness and nano-structures [95, 125]. Furthermore, anodic films, in comparison with oxide layers developed from chemical etching, are less inclined to crack and peel from age or wear due to a greater force and adhesion [126]. After creating surface roughness, the grafting of low surface energy materials is necessary to develop superhydrophobic surfaces. Zhang et al. [97] used aluminum foil and a graphite plate as an anode and cathode, respectively, in an oxalic acid aqueous solution having a magnetic stirrer surrounded by ice-water (Figure 6). The process was accomplished by using different currents at a specific time with subsequent modification of the surface to create superhydrophobic surfaces. 


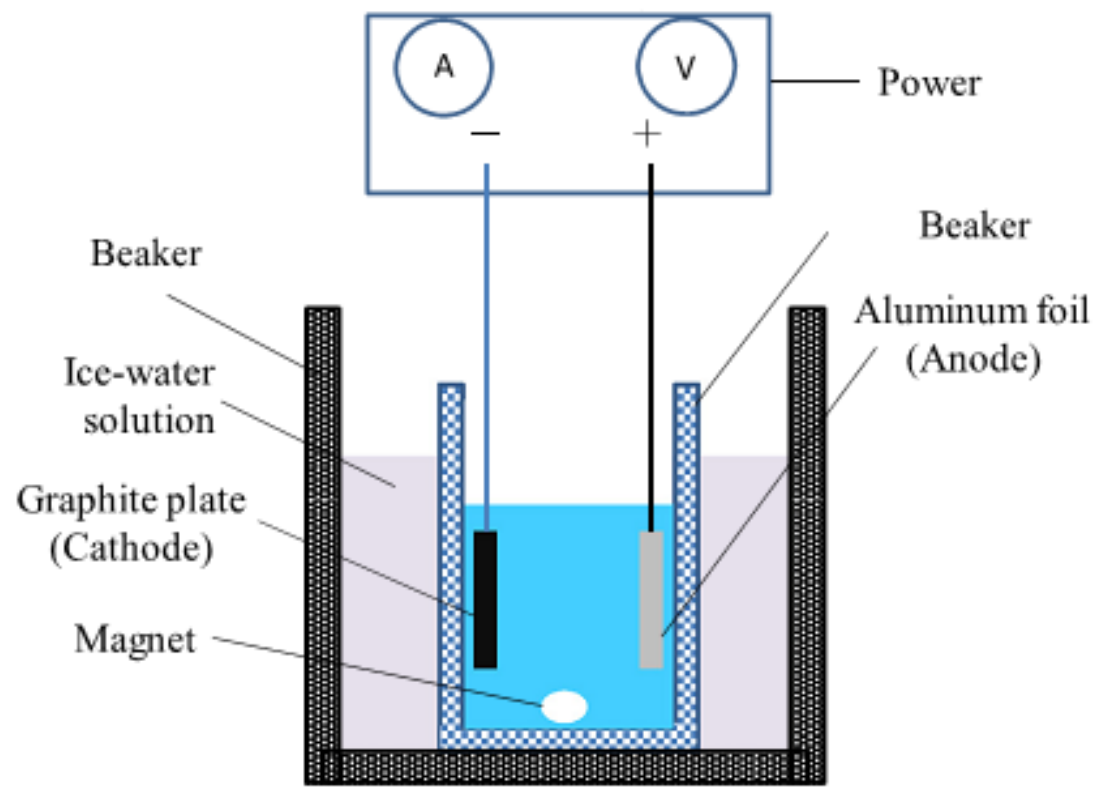

Figure 6: Schematic of electrochemical anodization [97].

\subsubsection{Electrodeposition}

Electrodeposition is an effective technique for fabricating superhydrophobic coatings on various substrates due to its low cost, reproducible process, scalability, and simplicity that permit its use for a range of applications [34, 100, 127]. Furthermore, control of the formation of micro- and nano-structures can be easily obtained by adjusting the electrodeposition parameters [34, 127]. For instance, a pine cone-like hierarchical structure was electrodeposited onto a copper surface by using a traditional Watts' bath and a platinum anode. In this technique, a thin coating is deposited onto a conductive substrate from a solution containing ions or charged micro/nanoparticles [128, 129]. Figure 7 shows the electrodeposition process using magnesium as the cathode and platinum as an anode. The electrolyte solution consists of a blend of cerium nitrate hexahydrate and myristic acid in ethanol. The reaction between $\mathrm{Ce}^{3+}$ ions near the cathode with myristic acid occurs due to the DC voltage leading to the formation of cerium myristate. Meanwhile, free $\mathrm{H}^{+}$ions in the solution increase, some of them obtaining an electron to form $\mathrm{H}_{2}$ [130]. 


\section{Anode (Platinum plate)}

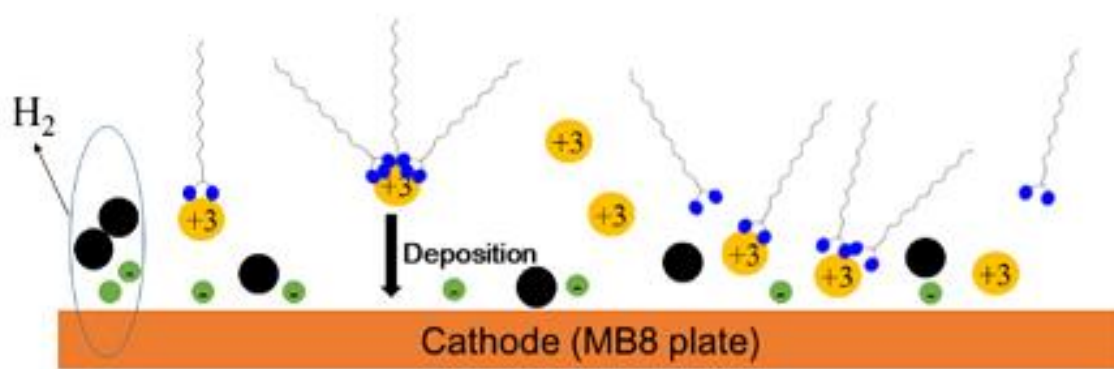

3) Cerium $\mathrm{H}^{+} \bullet \mathrm{e}^{-}:-m \sim \mathrm{CH}_{3}\left(\mathrm{CH}_{2}\right)_{12} \mathrm{COOH}$

Figure 7: The schematic diagram of the electrodeposition process [130].

\subsection{Application of superhydrophobic surfaces}

The superhydrophobic surfaces have recently attracted great attention due to their unique water repellency, self-cleaning, and anti-contamination properties $[44,49,131]$. These surfaces are used across a wide range of application areas, including self-cleaning [72, 129, 132], corrosion resistance [39, 133-135], anti-icing [7, 24, 25, 136-140], the separation of water and oil [26, 27, $87,141,142]$, the drag reduction of flowing fluids $[28,29,143]$, anti-fouling paints for boats [144, 145], anti-bacterial adhesion [146], windshields and architecture coatings [16, 147], and so on [19, 148-151]. In addition to the broad range of applications, there are many other advantages including a reduction in maintenance costs, elimination of monotonous manual effort, and also a reduction in the time spent in cleaning the final product [152].

Trapped air in cavities can reduce heat transfer between the droplet and solid surface leading to a delay in the time required for freezing. The progression of anti-icing properties with a delay in freezing on superhydrophobic surfaces offers practical solutions for eliminating the aforementioned issues [7, 24, 153, 154]. Oil-water separation is another application of superhydrophobic surfaces. The noticeable difference between water surface tension $(72 \mathrm{mN} / \mathrm{m}$ ) 
and oil surface tension (ca. $30 \mathrm{mN} / \mathrm{m}$ ) produces the oleophilic or superoleophilic properties of superhydrophobic surfaces. Consequently, superhydrophobic surfaces can be considered as favorable options for the cleanup of oil spills [27, 87]. The significant drag reduction of fluid flow over superhydrophobic surfaces is useful for decreasing the required pumping power [29]. The anti-contamination properties of superhydrophobic surfaces in solar cells prevents reductions in their efficiency $[16,17]$.

Finally, superhydrophobic surfaces hinder the corrosion of metals and alloy surfaces. The formation of a layer of air as a barrier between a superhydrophobic metal substrate and a liquid provides remarkable opportunities in the anti-corrosion of metal compounds [39]. This subject will be discussed profoundly in the following section.

\section{Corrosion}

Corrosion is defined as "the physico-chemical interaction between a metal and its environment, which results in changes in the properties of the metal and which may often lead to impairment of the function of the metal, the environment, or the technical system of which these form a part" [155]. Under normal environmental conditions, corrosive reactions progressively deteriorate surfaces, particularly the surfaces of reactive metals, surfaces that are used extensively in industrial applications. Globally, annual costs related to infrastructure corrosion are at least $\$ 1.8$ trillion US. This represents $3-4 \%$ of the gross domestic product of industrialized countries [156]. Figure 8 illustrates damage associated with highly corroded surfaces. In addition to pollution, humidity, salt, acids, and bases are the main corrosive environments that severely corrode metal and/or alloy surfaces [157]. Corrosion involves two different processes. At active areas (anodes), the movement of metal ions into solution produces an ionic current in the solution. At less active areas (cathodes), passage of electrons from a metal to an acceptor such as oxygen, another oxidizing agent, or 
hydrogen ions creates an electronic current in the metal [158]. Most of the time, the formation of pits or cracks in the surface is a sign of corrosion inception. This pitting of the surface continues to spread throughout the material as long as the material is in contact with the corrosive environment. This scenario results in extensive damage to surfaces [159].

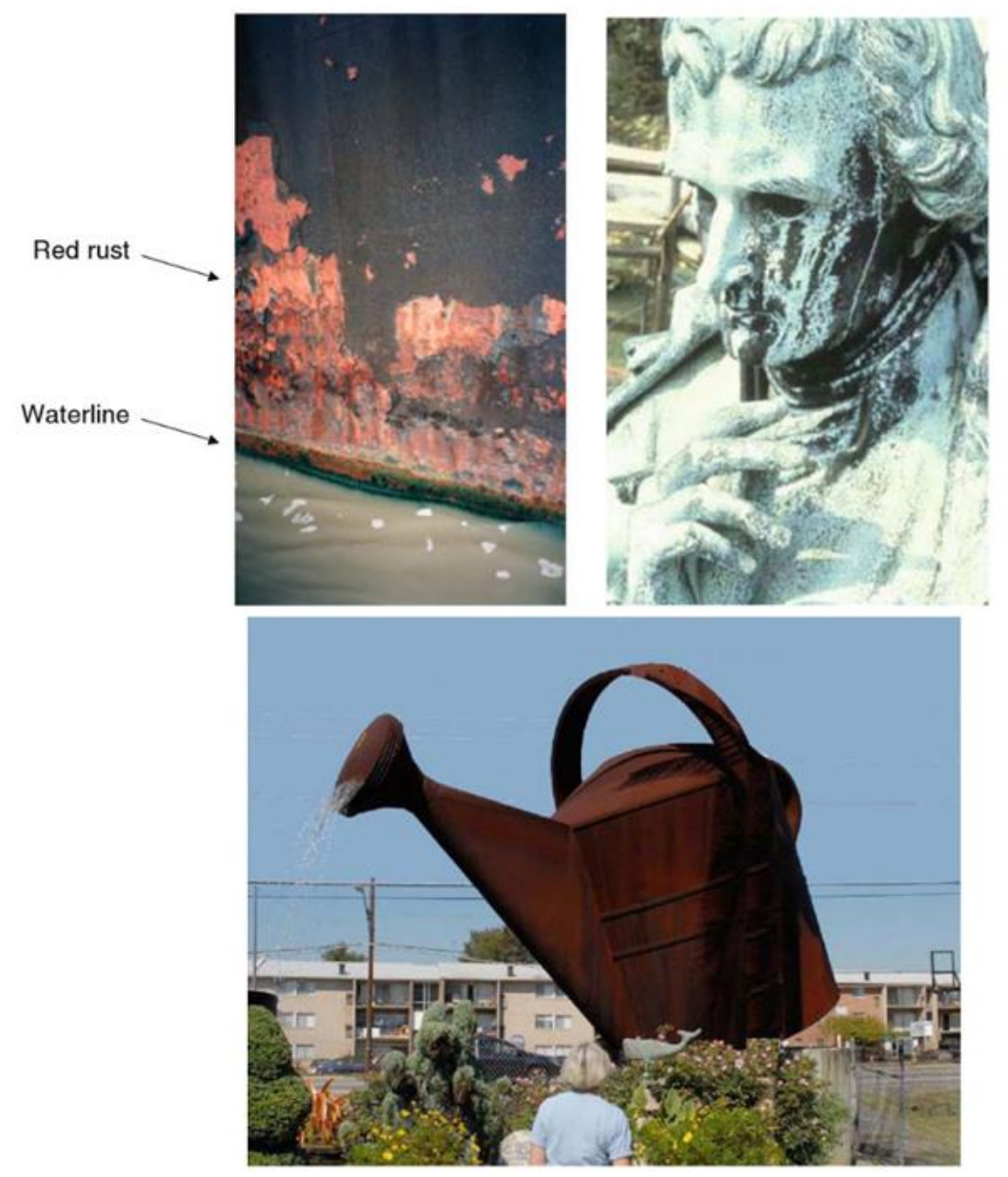

Figure 8: Images of corroded surfaces of ships and outdoor artworks [160].

Numerous techniques have been used to inhibit the corrosion of the metallic surfaces including chemical conversion coatings, sacrificial anodic coatings or metal painting, and cathodic protection [161-164]. Chemical conversion coatings include simple chemical treatments to create protective coatings. The painting of metals or use of sacrificial coatings can be used for aesthetic reasons and to also act as a barrier against corrosive elements. The widespread application of anti- 
corrosive layers, such as painting and chemical conversion coating using chromium compounds, is, however, highly restricted considering their detrimental effects on human health and the environment [165-167]. Cathodic protection of a metal surface is useful and environmental friendly. Nevertheless, this method is impracticable for industrial applications as it is too expensive to apply to large exposed surfaces. The high cost of cathodic protection, environmental restrictions related to the waste and disposal of heavy metals, and the toxic effects of chromium species have fostered a search for effective and more environmental friendly alternatives to combat the corrosion of surfaces $[101,168,169]$. Superhydrophobic surfaces are one suitable candidates for improving the corrosion resistance of metal substrates.

\subsection{Corrosion resistance of superhydrophobic surfaces}

Superhydrophobic surfaces are being investigated as a solution to reduce the corrosion of the metal substrates like aluminum, copper, magnesium, and steel alloys. There are two main situations in which the metal substrates can be corroded including immersion in corrosive solution and exposure to the humid air. As shown in figure 9(a), the contact of the metal with the solution containing corrosive ions could easily corrode the surface. Whilst the air trapped in the surface grooves of superhydrophobic substrates could act as an inherent insulator and hinder direct contact between the corrosive media and the material. It leads to the corrosion resistance of superhydrophobic surfaces [77, 170-172]. Moreover, Wang et al claimed that for the superhydrophobic surfaces immersed in corrosive solution medium, the surface chemical composition, especially the presence of long-chain hydrophobic groups, plays more important role in corrosion resistance in comparison to the surface morphology [173]. 
(a) In corrosive solution medium

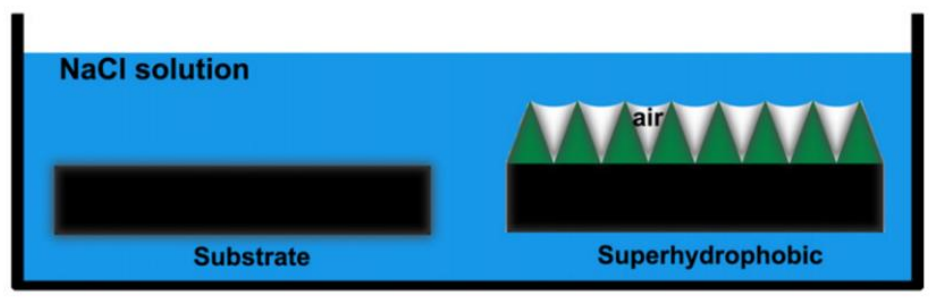

(b) In humid air

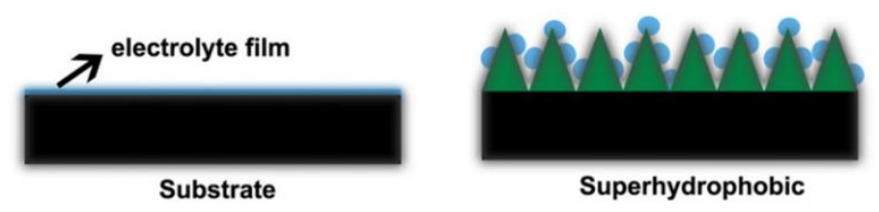

Figure 9: Models for corrosion resistance of superhydrophobic surfaces (a) in corrosive solution; (b) in humid air [171].

On the other hand, during exposure of the sample to the humid air, the electrolyte film would form due to the change of temperature and condensation of water vapor (Figure 9(b)). As the electrolyte film is the carrier of electron, oxygen and carbon dioxide, the formation of electrolyte film results in a sudden increase in corrosive rates [173]. On the superhydrophobic surface, the droplets created after the condensation are isolated from each other among the surface asperities and the electron cannot move freely. Consequently, the electro chemical reaction is hindered and leads to a low corrosive rate of superhydrophobic surfaces [171]. Furthermore, it is worthwhile to note that in comparison to surface chemical composition, the surface morphology has more effect on corrosion resistance of superhydrophobic surfaces in humid air [173].

In regard to the different types of applications, there are numerous options for evaluating corrosivity such as using deionized water, hydrochloric acid ( $\mathrm{HC} 1), \mathrm{KCl}, \mathrm{Na}_{2} \mathrm{HPO}_{4}, \mathrm{NaHCO}_{3}$, etc. Moreover, corrosion is assessed using weight loss measurements, neutron reflectivity, potentiodynamic curves, and electrochemical impedance spectroscopy (EIS). The latter two methods are the most practical means recently being used [159]. 


\subsection{Corrosion issues on aluminum surfaces}

Aluminum is one of the most abundant metallic elements in the Earth's crust, used for its good thermal and electrical conductivity, high-specific strength, low specific weight, and barrier properties. More than 40 million metric tons of aluminum are produced annually [174-176]. The applications of aluminum alloys vary from household items, packaging, electrical appliances, shipping, and construction, to aerospace, aircraft, and national defense applications [12, 177-179]. The corrosion resistance of aluminum in oxidizing media (air or water) is attributed to its inherent and continuous surface oxide layer $\left(\mathrm{Al}_{\mathrm{x}} \mathrm{O}_{\mathrm{y}}\right)$ having a thickness of a few nanometers, which dramatically prevents subsequent oxidation. However, in some cases, exposing aluminum to high concentrations of acids or alkaline solutions dissolves this oxide layer making it extremely vulnerable to corrosion. This stable layer can also be broken down by a localized attack in the presence of aggressive anions — such as halides, especially chloride ions — in solutions having $\mathrm{pH}$ values between 4 and 9 [180-183]. Consequently, many approaches have been used to improve the corrosion resistance of aluminum alloys in different environments.

Fabrication of superhydrophobic coatings on aluminum surfaces is a promising technique to slow down or even prevent the degradation of the aluminum oxide layer. The improved corrosion resistance of superhydrophobic surfaces relative to bare substrate is due to the presence of "air valleys" lying between the hierarchical structures of superhydrophobic surfaces and the corrosive environment. The variety of methods that have been used to construct superhydrophobic surfaces can be divided into two categories: one-step and two-step methods. One-step methods offer a simple way for the scaled-up production and industrial application of superhydrophobic surfaces in which roughening the surface and its modification occurs in a single step [184]. Jafari and Farzaneh [84] prepared a superhydrophobic surface using an environmental friendly and 
inexpensive method of spray coating of $\mathrm{SiO}_{2}$ or $\mathrm{CaCO}_{3}$ nanoparticles in stearic acid. A nanocomposite of $\mathrm{Al}_{2} \mathrm{O}_{3}$ nanoparticles added to the silicone rubber solution was then applied as a surface coating by spin coating method. A hierarchical superhydrophobic structure like that of lotus leaves was achieved resulting in better corrosion resistance. The amount of surface free energy was reduced by two orders of magnitude [7]. Song et al. [185] used fluoroalkylsilane in a sodium chloride aqueous solution as an electrolyte to make a superhydrophobic surface via onestep electrochemical machining. Numerous micro-scale rectangular plateaus were formed on the pits and protrusions of the rough structure.

One of the most common approaches for fabricating superhydrophobic coatings on aluminum surfaces is anodization. Anodization has been used as a one-step method to improve the anticorrosion properties of aluminum alloys. Porous- and barrier-type of aluminum surfaces were achieved by anodization in the presence of an aqueous $\mathrm{H}_{2} \mathrm{SO}_{4}$ solution and aqueous $\mathrm{H}_{3} \mathrm{BO}_{4}$ solution, respectively [180]. The electrolyte solution of sodium molybdate in sulfuric acid was used as an alternative to chromic acid in the anodization process to improve the corrosion resistance of aluminum samples [186]. Liu et al. [187] developed a superhydrophobic aluminum surface having a contact angle of $171.9^{\circ}$ and low SA via the one-step anodization process. The resulting superhydrophobic surface exhibited a porous surface and good corrosion resistance.

Fabrication of superhydrophobic coatings through the anodization process as a two-step method followed by deposition of low surface energy materials can favor an increased resistance to corrosion. Anodization parameters can have a significant impact on the surface morphology leading to a drastic change of the surface non-wettability of samples [11,97, 187, 188]. An increase in some anodization parameters, including anodization time, anodization current density, and electrolyte temperature separately led to an increase in the contact angle and the reduction of SAs. 
Subsequently, further increases to these parameters resulted in a contact angle and an SA reaching a constant value or even a deterioration (Figure 10) [97, 188]. Figure 11 shows SEM images of the nano-structures of the oxide layer fabricated on aluminum in relation to anodization times. The increase of the oxide layer thickness from 3 to $30 \mu \mathrm{m}$ and the increased diameter of the pore-like nano-structures were observed as anodization time increased from 1 to 20 min. However, longer anodization times also led to thinner boundaries between the pores [11]. Achieving optimized parameters is therefore critical to obtain optimal superhydrophobic surfaces.
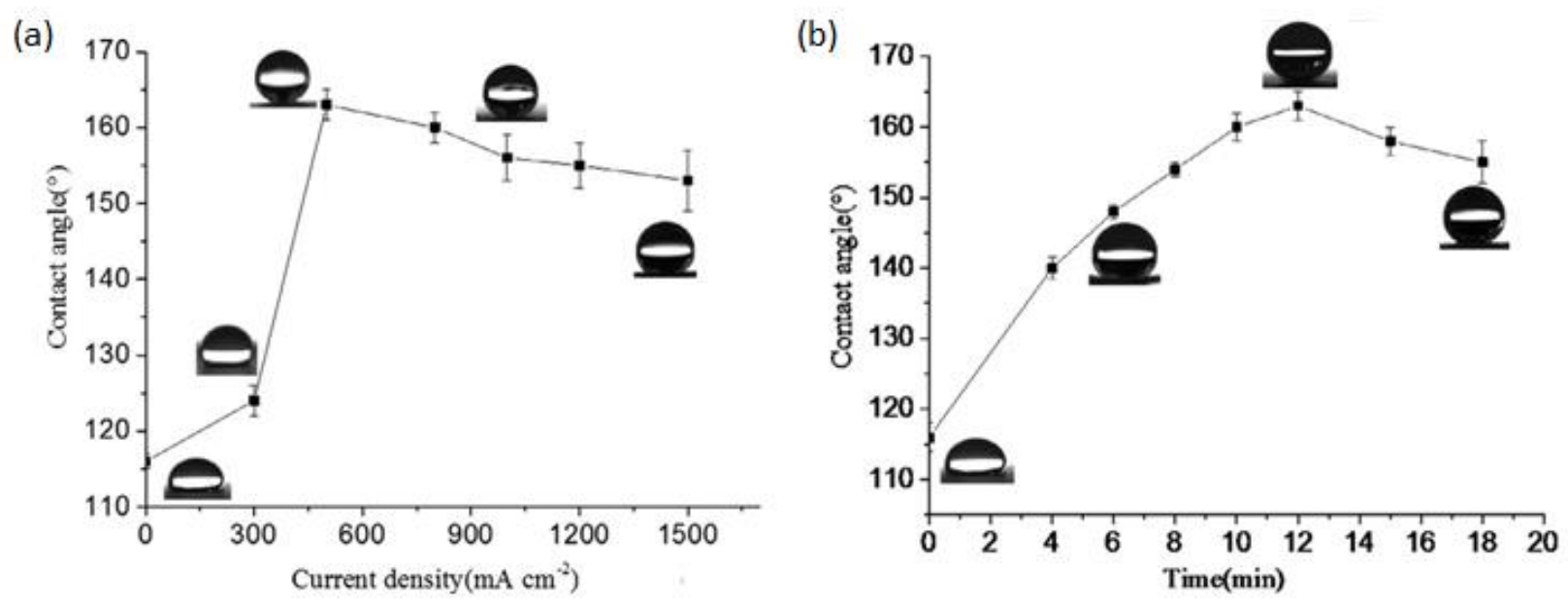

Figure 10: (a) The effect of anodization current density; (b) anodization time on the water contact angle [97]. 


\section{Anodization time}

(i)

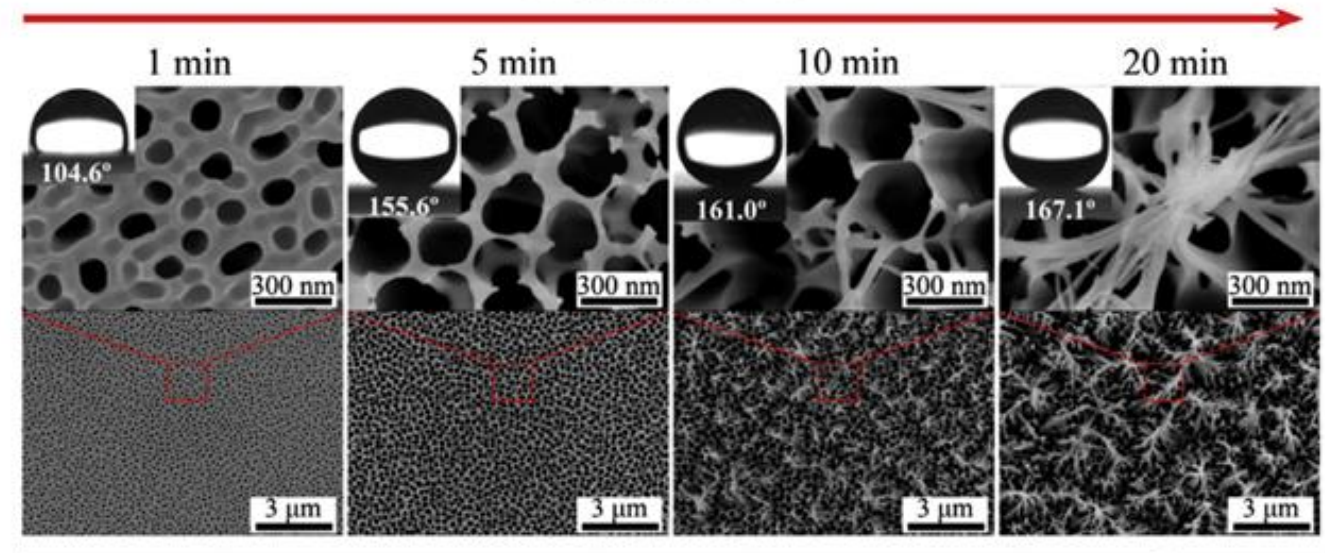

(ii)

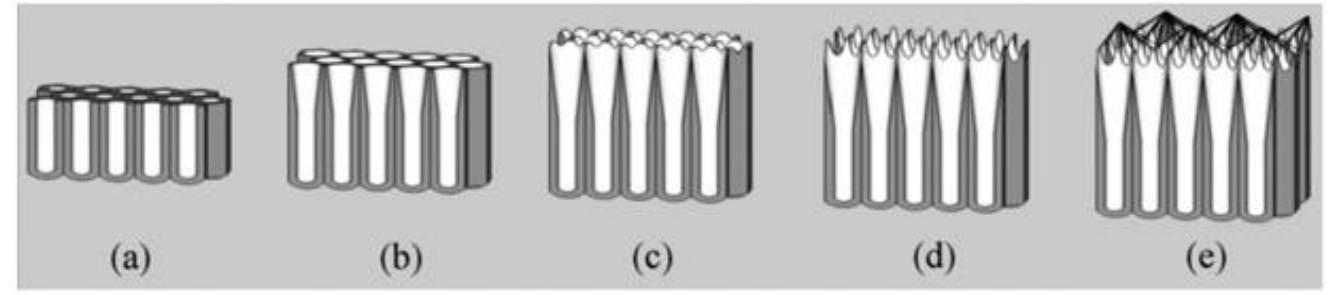

Figure 11: (i) SEM images of aluminum oxide nano-structures fabricated over aluminum surface with varying anodization intervals from 1 to $20 \mathrm{~min}$; (ii) The morphological evolution of the aluminum oxide layer during the anodization process [11].

Another point of interest is to apply a decent modifier to improve the superhydrophobicity. Low surface energy materials such as long chain fatty acids can be applied as surface modifiers to decrease the surface energy of an anodized aluminum surface. A superhydrophobic coating having a high corrosion resistance was achieved by anodized aluminum alloys modified with myristic acid. The oxide layer, covered by intertwined nanowires, formed on the surface having a WCA of $155.6^{\circ}$ and an SA of 5.7 ${ }^{\circ}$. Electrochemical measurements indicated that the anti-corrosion potential of the superhydrophobic coating increased significantly. The corrosion current density decreased by more than four orders of magnitude compared to that of untreated surface (Table 1) [96]. Similar results have been reported by other researchers [11, 189-191]. 
Low surface energy chemicals containing fluorine are also commonly used as surface modifiers in two-step methods. Peng et al. [188] evaluated the superhydrophobicity and corrosion resistance of an aluminum surface comparing two modifiers, $1 \mathrm{H}, 1 \mathrm{H}, 2 \mathrm{H}, 2 \mathrm{H}$-perfluorodecyltriethoxysilane (PDES) and stearic acid. Regardless of the modifier used, surfaces were similar with high contact angles and an $\mathrm{SA}$ as low as $0^{\circ}$. However, electrochemical results indicated that surfaces modified with PDES had more positive corrosion potential and lower corrosion current densities than those treated with stearic acid. Therefore, PDES seems to be the better choice for enhancing the corrosion resistance of aluminum surfaces.

Table 1: The results of potentiodynamic polarization curve of aluminum alloys with and without superhydrophobic coatings in a $3.5 \mathrm{wt} \% \mathrm{NaCl}$ solution [96].

\begin{tabular}{llll}
\hline Samples & $\mathbf{E}_{\text {corr }}(\mathrm{V})$ & $\mathbf{i}_{\text {corr }}\left(\mathbf{A} / \mathbf{c m}^{2}\right)$ & WCA ( $)$ \\
\hline Untreated sample & -0.838 & $2.733 \times 10-^{7}$ & $84.6 \pm 0.4$ \\
Superhydrophobic sample & 0.403 & $9.965 \times 10-{ }^{11}$ & $155.6 \pm 1.0$ \\
\hline
\end{tabular}

Similar results were obtained from the electrochemical anodization of aluminum followed by a grafting of long chain saturated fatty acids, perfluorinated fatty acid (PFODA), and perfluorsulfonic acid-polytetrafluoroethylene copolymer (PFSA). It was found that the lower surface energy of fluorine-containing modifiers - relative to fatty acids - led to higher contact angles and a better superhydrophobicity. Electrochemical tests showed that anodized aluminum grafted to PFODA had a much lower corrosion current density in comparison to the bare substrate and anodized aluminum (Figure 12), again representing a better corrosion resistance [177]. Qian and Shen [114] described a simple surface roughening method by chemical etching on polycrystalline aluminum in a Beck's dislocation etchant and further modification with 
fluoroalkylsilane. The depth and width of the etched pits was positively related to the duration of etching. Following the treatment with fluoroalkylsilane, the etched metallic surfaces exhibited superhydrophobicity. Shi et al. [192] modified an acid-etched hydrophilic aluminum substrate by using nano-silica particles and fluorosilane coating. Finally, a superhydrophobic aluminum surface having a WCA of $155.7^{\circ}$ was prepared by using hydrochloric acid followed by potassium permanganate passivation and modification by fluoroalkyl-silane. The surface showed hierarchical terrace-like structures and nano-scale coral-like network of bulge structures. Consequently, a corrosion inhibition efficiency of about $83 \%$ was obtained in comparison to the conventional twosteps method of etching and modification [31].

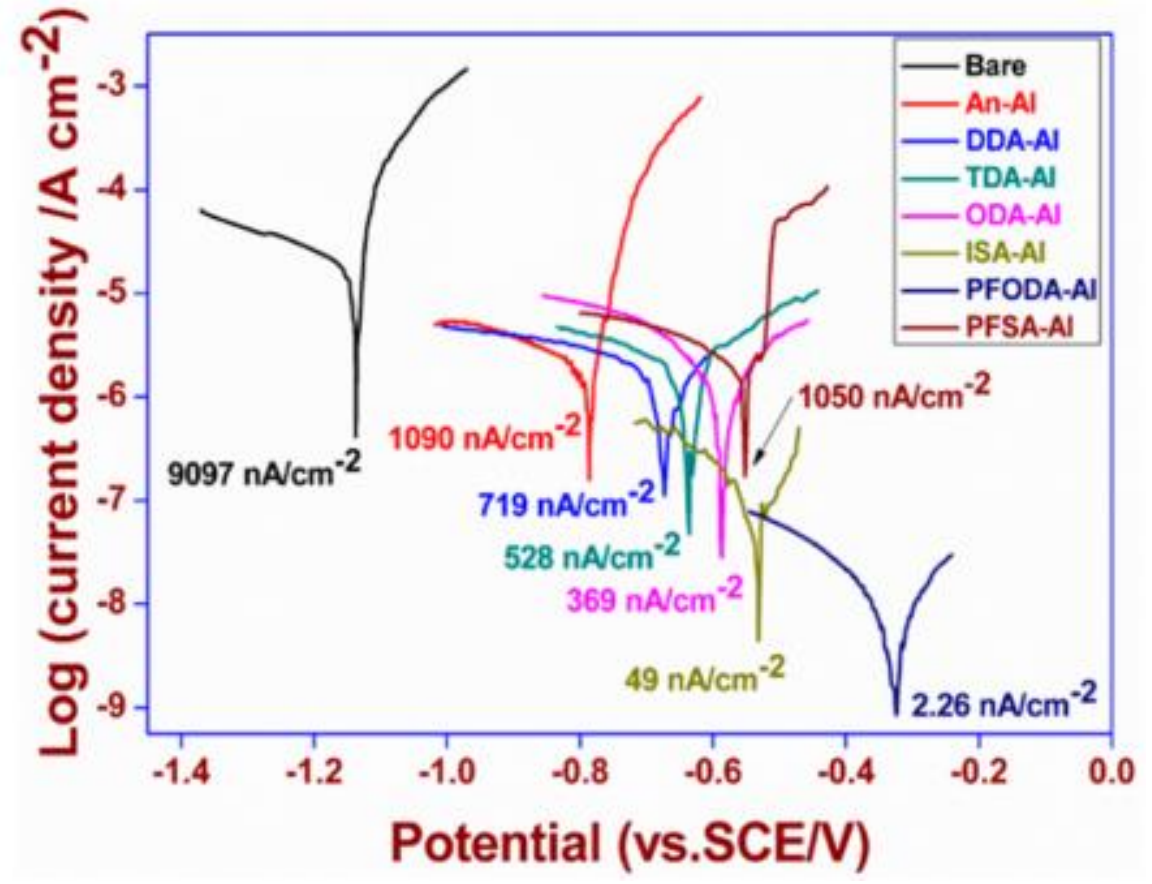

Figure 12: Polarization curves of the bare, anodized, and chemically modified anodized aluminum surface immersion in $3.5 \mathrm{wt} \% \mathrm{NaCl}$ solution for $30 \mathrm{~min}$ [177]. 


\subsection{Corrosion issues on copper surfaces}

Copper is an important material used in a wide range of applications owing to its excellent electrical and thermal conductivity, mechanical workability, fine appearance, malleability, and relatively noble properties [95, 193]. Copper is used as a conductor in electrical power lines, in pipelines for domestic and industrial water utilities, and as heat conductors and heat exchangers [194]. However, copper as an active metal is susceptible to corrosion, particularly in the presence of aggressive ions like chloride. The impact of chloride on copper corrosion within a corrosive environment depends on the concentration of chloride, so that unstable films of $\mathrm{CuCl}$ and $\mathrm{CuCl}_{2}^{-}$ formed at lower concentrations and $\mathrm{CuCl}_{3}^{-}$and $\mathrm{CuCl}_{4}^{-}$formed at higher concentrations $[195,196]$. Therefore, preventing the corrosion of copper has attracted much attention over the past years. Organic inhibitor-containing polar groups [197], heterocyclic compounds such as azole derivatives [195, 198-200], and conjugated double bonds [201] have been applied as copper corrosion inhibitors. The main disadvantage of these inhibitors is their inherent toxicity having risks to the environment and human health [202]. Self-assembled monolayers (SAMs) are another prevalent approach that is limited in application due to its poor durability [203]. Moreover, the poor adhesion and water permeability of the electroactive conducting polymer coatings (ECPs) restricts its use as an anti-corrosive coating in very aggressive environments [204]. Therefore, a substitute method for providing an effective, environmentally friendly, and long-lasting protection against copper corrosion is sought. Superhydrophobic coatings represent an interesting approach for inhibiting corrosion by reducing the contact area between water and copper surfaces. As such, research has been carried out developing superhydrophobic surfaces on copper substrates by means including electrodeposition [34, 100, 205, 206], anodization [95, 207], wet chemical reaction [32, 208], and sol-gel [33, 101]. 
The advantages of the electrodeposition process are its low costs, ease of control, and versatility. Use of the electrodeposition process and adjusting the related parameters can be a relatively simple way to control surface morphology and non-wettability [100, 127, 206, 209]. For instance, with the increase in deposition time, the morphology of the cathodic copper surface transformed from blossom buds into nanostructure assemblies, flowers, and then into nanorods [209]. Liu et al. [205], studying the effect of deposition time on surface adhesion, showed that as deposition time increased, there was a transition of the wetting state from the high adhesive petal effect to the low adhesive lotus state and a higher corrosion resistance due to this alteration of surface morphology. The stability of superhydrophobic surfaces is an important factor when assessing performance in corrosion inhibition as a lack of durability and stability is a limiting factor for the practical application of superhydrophobic surfaces. Long-term stability is verified by testing the superhydrophobicity of samples after being in storage at ambient conditions for several months $[33,193,206]$. The non-wettability of a superhydrophobic surface prepared via electrodeposition in an electrolytic buffer solution of zinc ions showed no significant difference after it was stored for about eight months. When compared to bare copper, superhydrophobic surfaces with long-term stability showed a 133-fold reduction of the corrosion rate and 99\% decrease of corrosion current density [206]. The chemical stability of superhydrophobic surfaces can be evaluated by testing the influence of the acidity of water droplets on the non-wettability of the surface. Most studies showed a negligible variation of contact angle and an SA across $\mathrm{pH}$ values ranging from 1.0 to 14.0 [193, $205,210]$. One of the major factors for the practical application of superhydrophobic surfaces is mechanical stability. For instance, the change in surface roughness or impurities left on the surface as a result of abrasion leads to the reduction of non-wettability [211]. Despite the importance of mechanical stability, this has not been frequently studied. Figure 13 illustrates the destruction of 
hierarchical structures after pulling a weight on the surface for $1.0 \mathrm{~m}$ at an applied pressure of $6.0 \mathrm{kPa}$ leading to the decrement of the contact angle and increment of the SA. The hardness of the superhydrophobic surface was also greater than that of bare substrate [34].
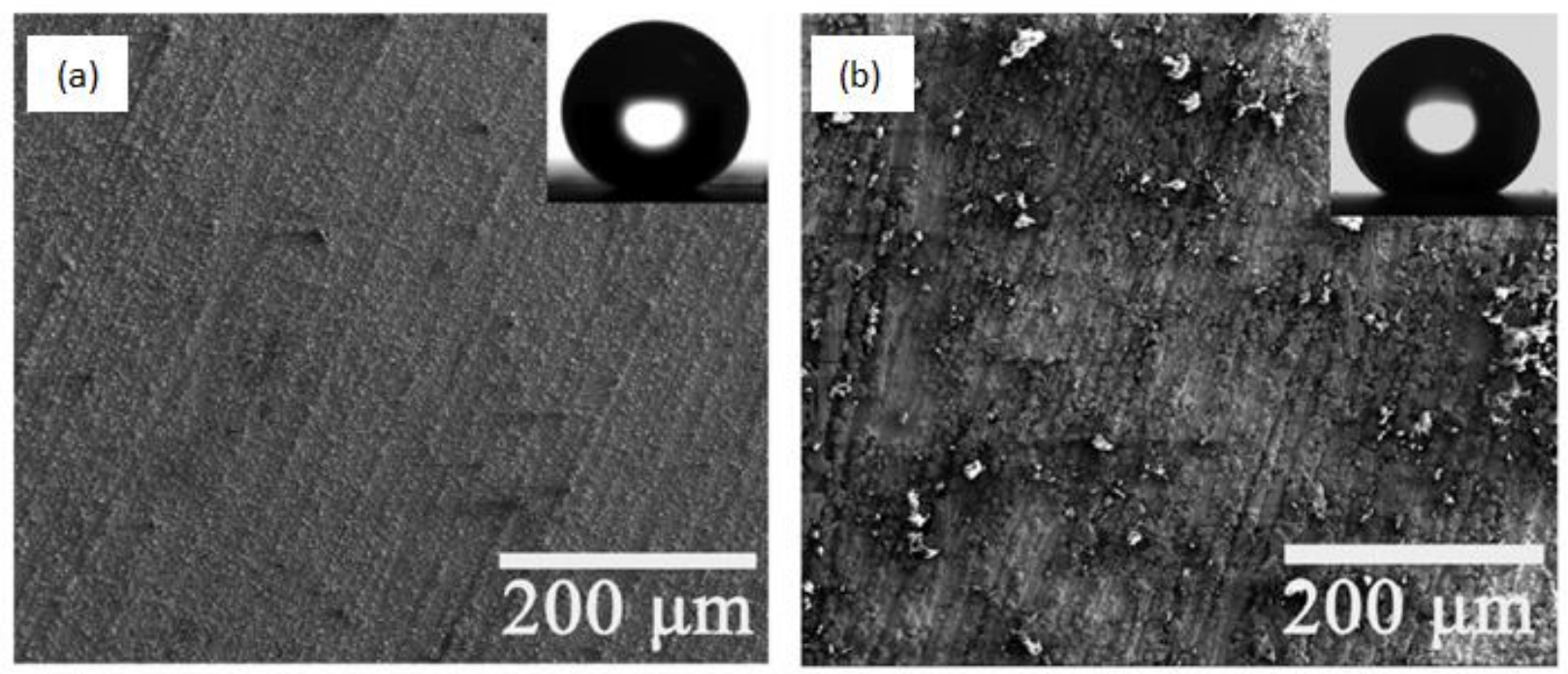

Figure 13: SEM images of the superhydrophobic surfaces (a) before abrasion; (b) after abrasion for $1.0 \mathrm{~m}$ at applied pressure of $6.0 \mathrm{kPa}$ [34].

Immersion time in corrosive environments also plays an important role in the corrosion behavior of a given surface. Su et al [34] studied the effect of immersion time on the non-wettability properties of superhydrophobic surfaces fabricated using the electrodeposition process in a traditional Watts' bath followed by a heating treatment in the presence of a fluorine-containing modifier. After six days of immersion in water, the contact angle of the surface remained $150^{\circ}$ and the SA was less than $10^{\circ}$. The non-wettability of a superhydrophobic surface prepared by the solgel method in a basic solution showed no difference after storage in air for three months. However, after 21 days of immersion in a $\mathrm{NaCl}$ solution, the contact angle appeared to be less than $150^{\circ}$ [101]. The deterioration of corrosion resistance of the superhydrophobic copper sulfide film under attack from chloride ions was also observed from the Bode plots after $48 \mathrm{~h}$ of immersion in a $\mathrm{NaCl}$ solution [210]. As shown in Figure 14 (a), the decrease of contact angle with an increase in 
immersion time is significant over the first four days. However, after five days or more, the contact angle remained almost constant around $140^{\circ}$. The polarization curves showed the increase of current densities with the immersion time indicating the deterioration of barrier capability of the film (Figure 14 (b)) [212]. Other studies have confirmed these results [33, 202, 209, 213].
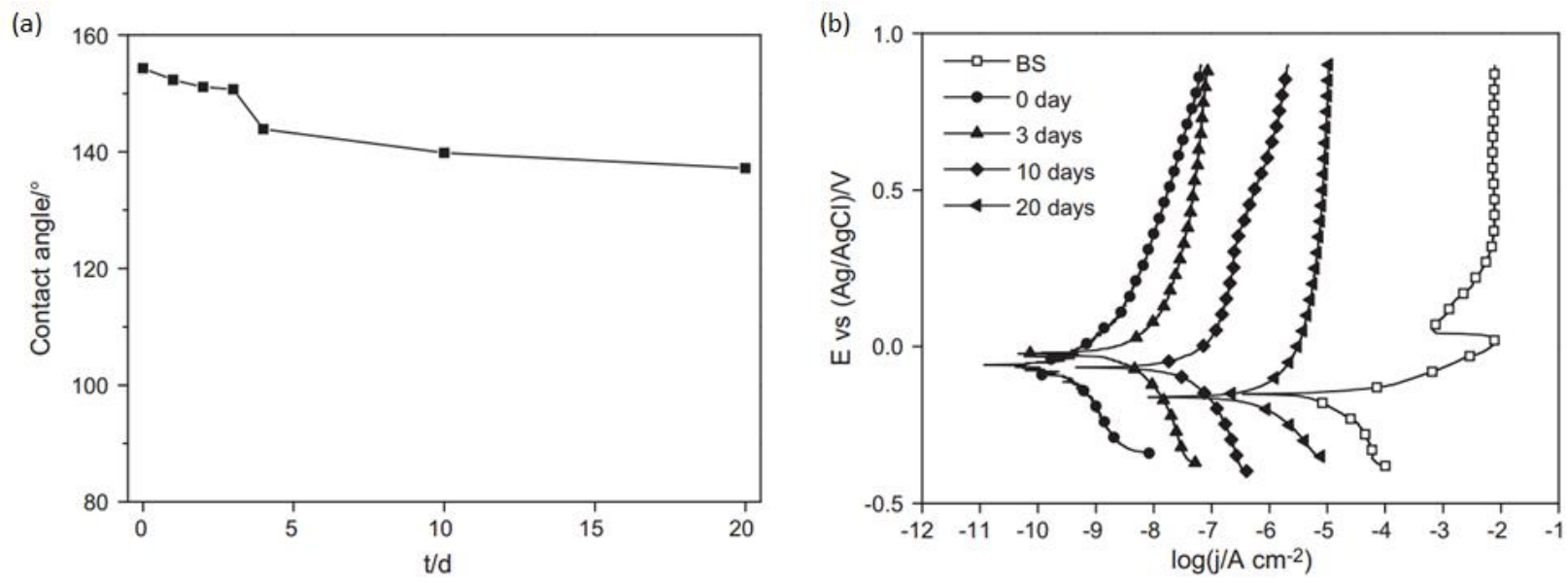

Figure 14: (a) The effect of immersion time on the contact angle of a superhydrophobic surface placed in a $\mathrm{NaCl}$ solution; (b) The polarization curves of bare substrate and a superhydrophobic surface as a function of immersion time in a $\mathrm{NaCl}$ solution [212].

The study of the effect of capillarity and the immersion depth in a $\mathrm{NaCl}$ solution on corrosion behavior showed that the $\mathrm{NaCl}$ solution could be in contact with the superhydrophobic film via the two different models of Cassie-Baxter and Wenzel depending on the immersion depth [208]. As the superhydrophobic film was immersed deeper into a $\mathrm{NaCl}$ solution, liquid penetrated the cavities and followed the Wenzel model. On the other hand, as immersion depth decreased, the Cassie model was attained with bright superhydrophobic surfaces and a higher stability. The interface model and equivalent circuits of superhydrophobic surfaces in the Cassie and Wenzel models can be observed in Figure 15 and 16. 
(a)

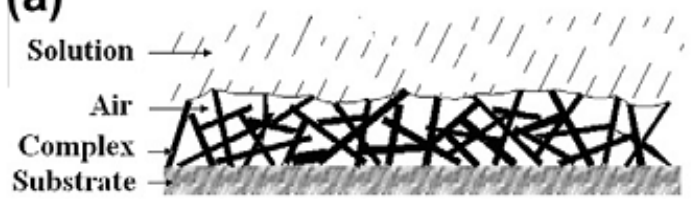

(b)

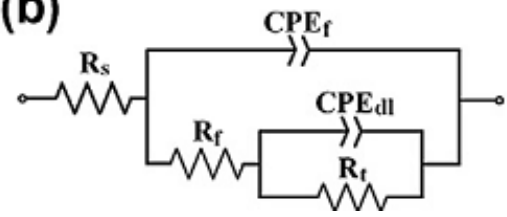

(c)

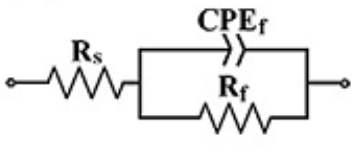

Figure 15: (a) The interface model; (b) and (c) equivalent circuits in the Cassie mode for the superhydrophobic sample placed in a $3.5 \% \mathrm{NaCl}$ solution [208].

(a)

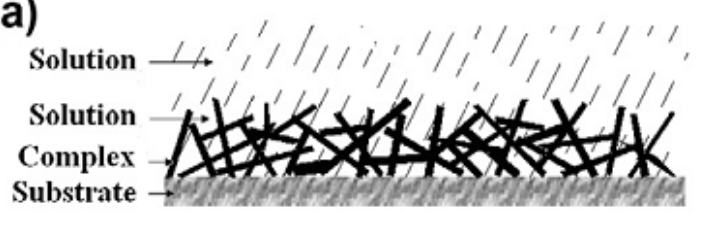

(b)

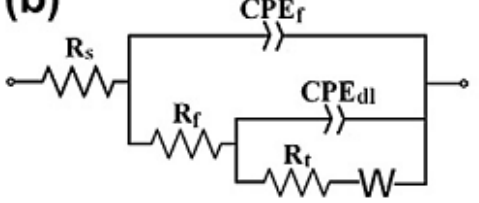

(c)

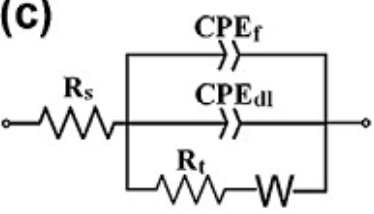

Figure 16: (a) The interface model; (b) and (c) equivalent circuits in the Wenzel mode for a superhydrophobic sample immersed in a 3.5\% $\mathrm{NaCl}$ solution [208].

\subsection{Corrosion issues on magnesium surfaces}

Magnesium is one of the most promising green engineering materials and the lightest of all metals used as the basis for constructional alloys. This material possesses many favorable characteristics including a high strength to weight ratio, low specific gravity, high thermal conductivity, good shock adsorption capacity, good machinability, and recyclability. Magnesium and its alloys have attracted great interest due to their potential applications as biological materials and their use in the automotive, aerospace, and electronic industries [129, 214]. The high affinity of $\mathrm{Mg}$ for oxygen leads to the formation of a thin layer of magnesium oxide on its surface in a dry air atmosphere. However, in the presence of even a low amount of relative humidity, the hydration of that oxide layer results in the formation of brittle layer of magnesium hydroxide $\operatorname{Mg}(\mathrm{OH})_{2}$ with a weak adherence to the metal [215]. Therefore, Mg corrosion easily occurs in aqueous solutions or in a humid atmosphere thereby seriously hindering its outdoor applications [129]. It is crucial to generate an anti-corrosive surface for $\mathrm{Mg}$ without sacrificing the dominant and favorable physical 
and mechanical properties. Chemical conversion, electroplating, and anodic oxidation are some means used to ameliorate the corrosion resistance of magnesium alloy [216, 217]. The formation of pores, pin holes, cracks, etc. during these methods is, so far, unavoidable. These defects provide channels into which water penetrates, deteriorating the corrosion resistance of magnesium alloys [211]. Fabrication of superhydrophobic coatings on $\mathrm{Mg}$ and its alloys is an effective means of reducing surface corrosion. Various methods have been employed to fabricate these surfaces such as etching $[88,89,171]$, electrodeposition $[129,211,218]$, wet chemical reactions [21, 219, 220], and hydrothermal synthesis [135, 221, 222].

Electrodeposition is a common method for the fabrication of superhydrophobic surfaces on magnesium alloys. Liu et al. [130] developed a one-step, environmental friendly technique to fabricate hierarchical micro- and nano-scale structures having a better corrosion resistance. The structures were made in the presence of cerium nitrate hexahydrate and myristic acid as a surface modifier. Liu and Kang [129] demonstrated that electrodeposition of a cobalt coating followed by modification with stearic acid produced cotton-like structures and leaf-like clusters on a superhydrophobic surface (Figure 17). According to the Cassie-Baxter equation, the area fraction of the air trapped within the interstices of the micro/nano-structures was $87.4 \%$. As such, the obtained superhydrophobic surface demonstrated excellent corrosion resistance [129]. 

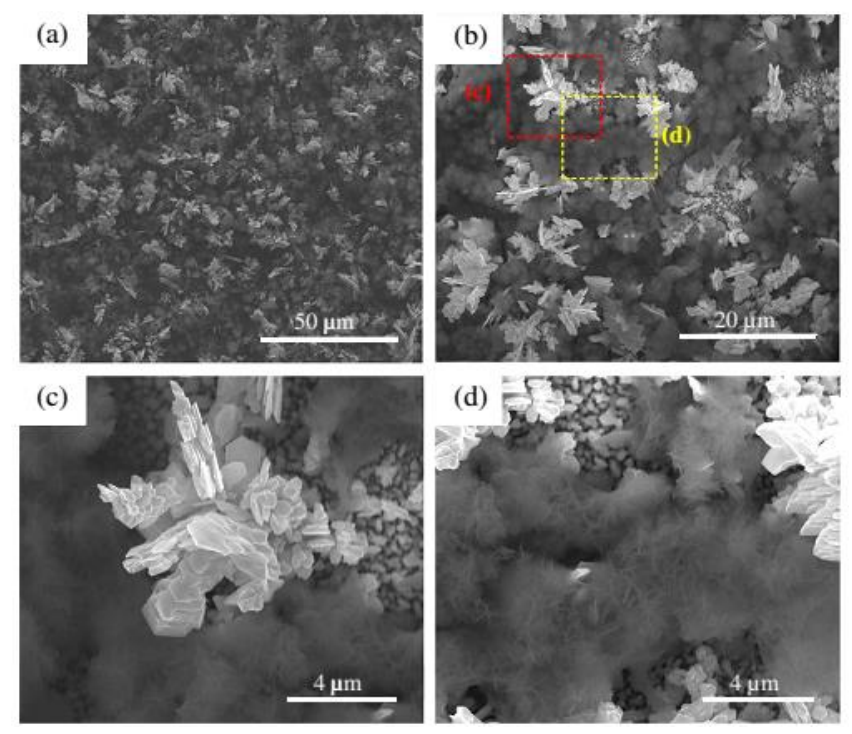

Figure 17: SEM images of the copper superhydrophobic surface at various magnifications [129]. Zn-Co coating with post-modification of the magnesium alloy had an attractive anti-corrosive behavior. The good stability of the rough texture on the surface was detected with the immersion test, finger pressing, and abrasion with sandpaper [211]. She et al. [223] achieved the pineconelike hierarchical structures by Ni electrodeposition on the magnesium surface. After modification with stearic acid, the as-prepared superhydrophobic surface showed a low corrosion rate that was only $0.003 \%$ of the bare magnesium alloy's rate with good mechanical and chemical stability. In another study, a highly anti-corrosive Ni-Co coating on magnesium alloy was prepared [218]. The addition of cobalt led to flower-like hierarchical structures and better superhydrophobicity. Furthermore, as seen in Table 2, a lower corrosion rate was observed on Ni-Co superhydrophobic surfaces relative to those containing Ni. In terms of combination of metal ions and fatty acids as a superhydrophobic coating, Wang et al. [224] developed a superhydrophobic surface by using a $\mathrm{Cu}$ coating and She et al. [225] electrodeposited a Cu-Zn alloy coating followed by modification with lauric acid. In the presence of $\mathrm{Cu}$, cylindrical forms with cone-shape structures were detected. However, feather-like $\mathrm{CuO}$ structures were formed on a surface coated by $\mathrm{Cu}-\mathrm{Zn}$. There was no 
difference in the superhydrophobicity and corrosion resistance for surfaces electrodeposited by $\mathrm{Cu}$ versus those by $\mathrm{Cu}-\mathrm{Zn}$ ions.

Table 2: The results of potentiodynamic corrosion test of the magnesium surface with and without superhydrophobic coating when immersed in a $3.5 \mathrm{wt} . \% \mathrm{NaCl}$ solution [218].

\begin{tabular}{lccl}
\hline Samples & $\mathbf{E}_{\text {corr }}(\mathbf{V})$ & $\mathbf{i}_{\text {corr }}\left(\mathbf{A} / \mathbf{c m}^{2}\right)$ & $\begin{array}{l}\text { Corrosion rate } \\
(\mathbf{m m} / \mathbf{a})\end{array}$ \\
\hline Bare substrate & -1.597 & $1.5 \times 10-^{5}$ & $3.3 \times 10-^{1}$ \\
Ni superhydrophobic surface & -0.333 & $2.0 \times 10-^{8}$ & $4.2 \times 10-^{4}$ \\
Ni-Co superhydrophobic surface & -0.172 & $9.2 \times 10-^{9}$ & $2.0 \times 10-^{4}$ \\
\hline
\end{tabular}

The hydrothermal method is another approach for obtaining uniform and reproducible superhydrophobic surfaces. A hydrothermal process, with subsequent modification with fluoroalkylsilane, was used to construct a flower-like hierarchical microstructure. As shown in Figure 18, numerous crystallites having a flake morphology formed these flower-like protrusions. After modification, the corrosion current density decreased by more than three orders of magnitude and the corrosion potential increased, meaning a greater corrosion resistance [226]. Gao et al. [214, 227] developed a superhydrophobic coating having a good corrosion resistance through use of a hydrothermal process in the presence of hydrogen peroxide and further modification with fluoroalkylsilane. By increasing the reaction time, the morphology of the szaibelyite evolved from a fibrous microstructure to spherical-like structures. 

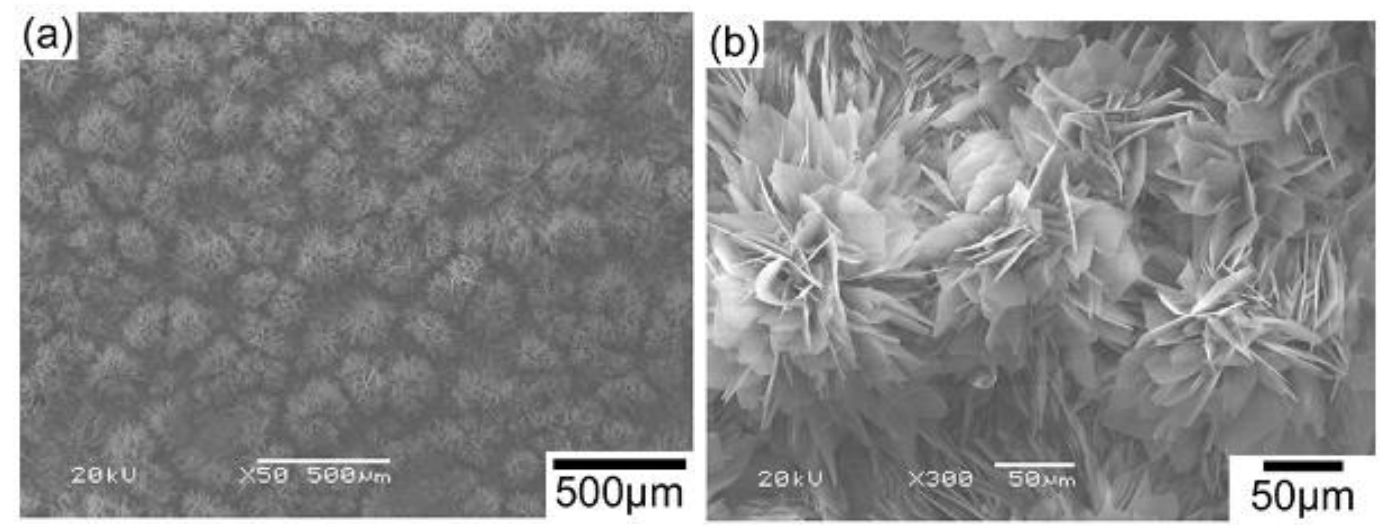

Figure 18: SEM images of the hydromagnesite film layer at different magnifications [226].

Post-modification of a hydrothermal-treated surface with stearic acid and PFOTES led to the petallike structure and an excellent corrosion protection [124, 221]. Ou et al. [124] compared hydrothermally-treated and chemically-etched samples. It was shown that superhydrophobic surfaces based on the hydrothermal technique were more effective in corrosion protection mainly because of the generation of hydroxide or oxide layers on the surfaces. Wang et al. [135] developed an anti-corrosion superhydrophobic surface with long-term stability and an anti-bacterial adhesion effect. After modification with stearic acid, the wettability of the surface had changed from superhydrophilicity to the superhydrophobicity. The corrosion behavior of the samples after a long-term immersion in Hank's solution are presented in Figure 19. After 80 days, the substrate had corroded significantly, however the corrosion area of the superhydrophobic sample was much smaller in comparison to the bare substrate and superhydrophilic samples. 


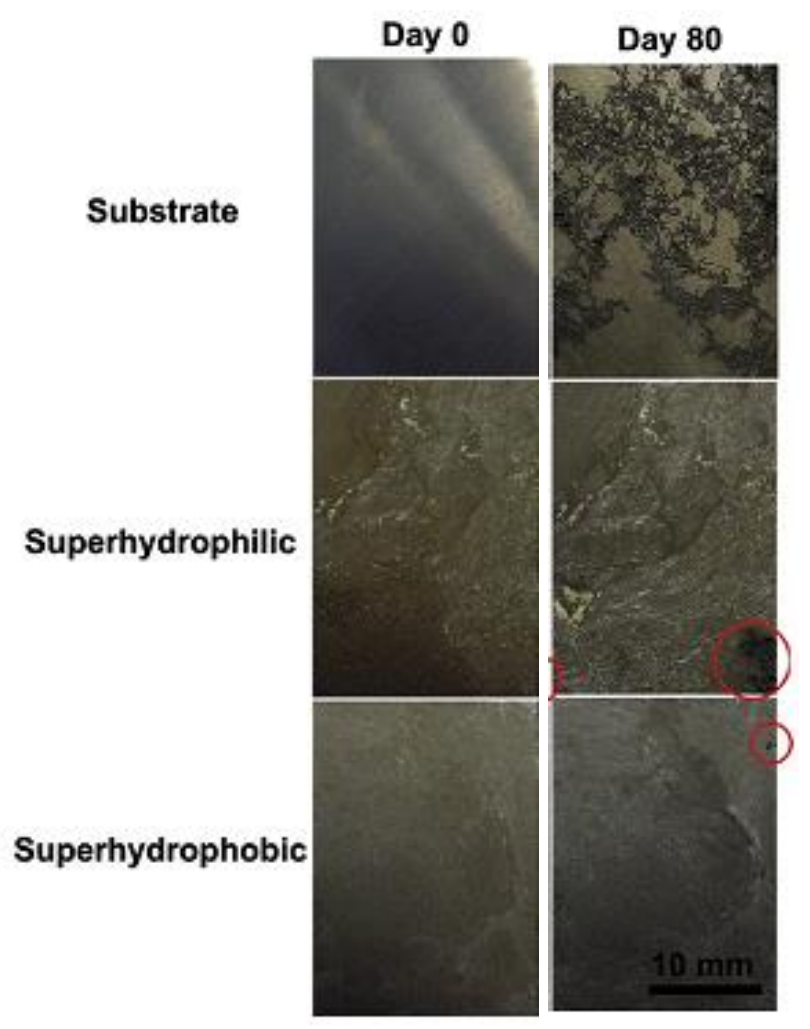

Figure 19: Optical images of the bare substrate, the samples with superhydrophilic film and superhydrophobic film after 80 days in Hank's solution [135].

\subsection{Corrosion issues on steel surfaces}

Steel and its alloys is one of the most essential and beneficial engineered materials and they play an important role in our daily lives as well as in industrial applications, such as construction, infrastructure, transportation, electrification, the maritime industry, etc. Annual worldwide production of crude steel is more than 1.5 billion tons [176, 228, 229]. There are thousands of different types of steel to fulfill the multiple purposes of use. Differences are based upon their chemical composition, often combinations of iron, carbon, chromium, tungsten, copper, aluminum, and manganese. Varying the amounts of alloying elements will modify its properties such as the hardness, ductility, and tensile strength. Carbon steel and stainless steel are the two well-established grades of steel. By increasing the carbon content in steel from $0.25 \%$ to $2 \%$, 
carbon steel is produced. Because of its low cost and high strength, carbon steel is one of the most common materials used in marine applications, chemical processing, petroleum production, refining, etc. Stainless steel is a low carbon steel generally containing 10-20\% chromium as the main alloying element and is valued for comparatively good corrosion resistance. The broad spectrum of stainless steel applications includes the petrochemical, construction, maritime, and aviation industries [230, 231]. However, even stainless steel is corroded under harsh conditions in the presence of halogen ions [99]. Despite the better corrosion resistance of stainless steel, carbon steel is widely used in corrosive media as the cost per weight and cost per sample is 4-6x and 9$14 \times$ cheaper, respectively [232-235]. The dominant cause of the failure of structures is steel corrosion. Evidently, steel corrosion is responsible for about $40 \%$ of structures' destruction assessed at as much as $\$ 14$ billion annually for the United States alone [236]. Consequently, it is a major challenge to increase the stability of steel alloys under corrosive environments. The development of superhydrophobic surfaces is of great interest to improve the corrosion resistance of steel and expand its applications. Etching [38, 119, 230], templating [113, 237, 238], spray coating $[3,239,240]$, and anodization $[94,241]$ are some of the techniques used to create superhydrophobic surfaces on steel substrates.

The study of the corrosion resistance of superhydrophobic nanocomposite coatings of metals in combination with an underlying oxide layer has attracted much attention [99, 102, 242]. A multilayer superhydrophobic nanocomposite coating atop oxide sublayers, including magnetite coatings and composite coatings produced by plasma electrolyte oxidation (PEO) have been developed for low carbon steel. The nanocomposite coatings on top of a PEO oxide coating showed more corrosion resistance and durability [102]. The silica nanoparticles were deposited on a PEO sublayer to prepare the anti-corrosive surfaces. The higher values of polarization resistance and 
impedance modulus having lower corrosion currents confirmed the better corrosion resistance of the superhydrophobic surfaces [242].

Nickel is one of the indispensable engineering materials due to its good properties like high corrosion resistance, hardness and magnetism. The anti-corrosive behavior of Ni-based superhydrophobic coatings fabricated by electrodeposition mechanism have been examined so far [128, 243, 244]. Xiang et al. [245] produced a superhydrophobic coating by electrodeposition of nickel with further surface modification with myristic acid on a low carbon steel. As shown in Figure 20, a great number of hierarchical starfish-like structure are deposited on the substrate at the current density of $8 \mathrm{~A} / \mathrm{dm}^{2}$. Furthermore, there were several void spaces and grooves among them leading to the higher air trapped content. As such, this achieved high WCA and good corrosion resistance. By using stearic acid as surface modification and at the current density of 60 $\mathrm{A} / \mathrm{dm}^{2}$, the surface was covered with homogeneously tortoise-shell-like structure [246]. A superhydrophobic surface with a WCA as high as $160.4^{\circ}$ was fabricated based on electrodeposited nickel-graphene hybrid film. The corrosion current density of superhydrophobic surface decreased up to $0.005 \%$ and polarization resistance showed about $1.88 \times 10^{4}$ times increase [247]. In the presence of tungsten disulphide nanoparticles, the surface roughness and consequently WCA and corrosion resistance was enhanced. By the increase of nanoparticle content up to $20 \mathrm{~g} \mathrm{dm}^{-3}$, the surface roughness was changed from coarse to porous surface. In addition, it leads to higher reduction of current density with good mechanical stability [248]. 

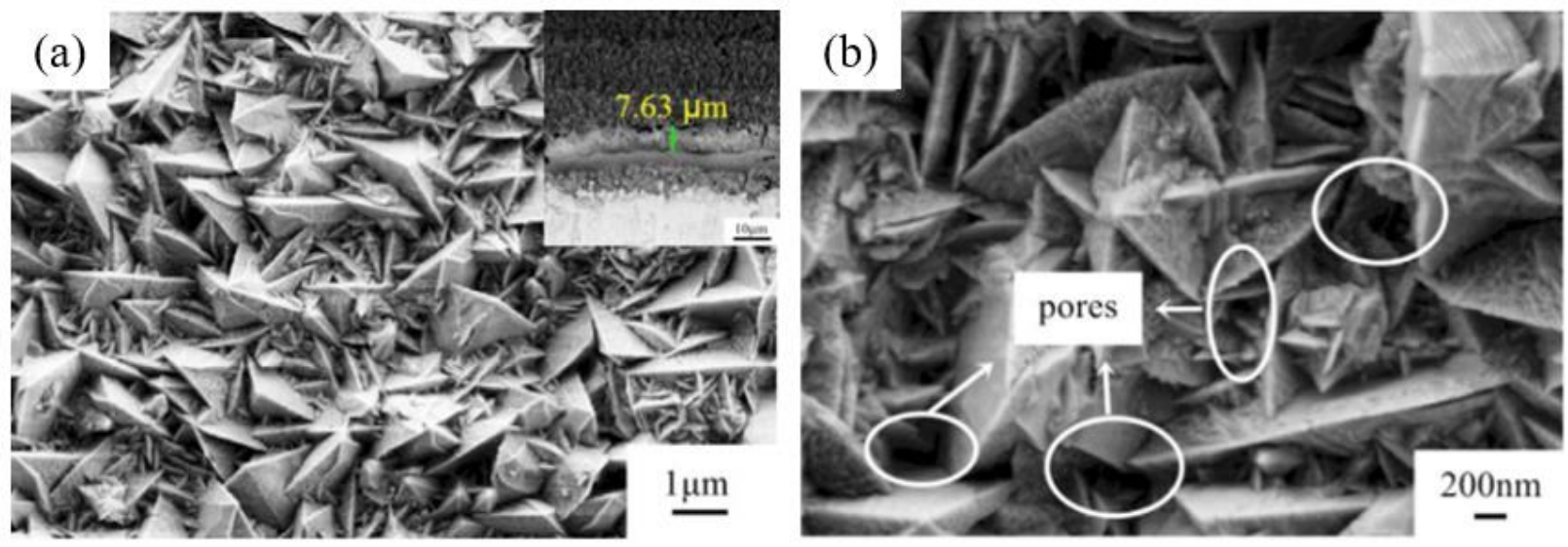

Figure 20: SEM images of the superhydrophobic nickel coatings at (a) low and (b) high magnification [245].

To fabricate superhydrophobic coatings, templating is another useful method. For instance, a Xanthosoma sagittifolium leaf was used as the template to replicate its papillary nano-structures by means of nanocasting onto cold rolled steel electrodes [237]. Formation of anodic protection of the electroactive epoxy coating that reduced corrosion rates and/or water repellency of the superhydrophobic coating led to the enhancement of corrosion protection. By replacing the epoxy with a polyaniline coating, which has a good processability and a comparatively low cost, Chang et al. [249] obtained many micro-scale mastoids covered by nano-scale wrinkles. Furthermore, the non-wettability and corrosion resistance of these coatings had an almost insignificant difference [113]. Chang et al. [249] also synthesized an electroactive polyimide and then used a nanocasting technique to replicate the nanostructure of Xanthosoma sagittifolium leaves. They produced a biomimetic superhydrophobic electroactive polyimide (SEPI) having a similar morphology as the leaf, a high WCA, and better corrosion resistance. Peng et al. [238] fabricated the superhydrophobic plant leaf structure onto cold rolled steel by means of environmentally friendly epoxy coating and nanocasting with a subsequent UV-curing technique. Rapid production rates, lower costs, and solvent free curing at room temperature are some of the advantages of UV-curing 
relative to other curing techniques. After keeping the steel at room temperature for one month, there were negligible changes of the WAC, confirming a good durability. As shown in Figure 21, they observed papillary-like microstructures, the reduction of the corrosion current density by more than two orders of magnitude, and more positive values of corrosion potential.
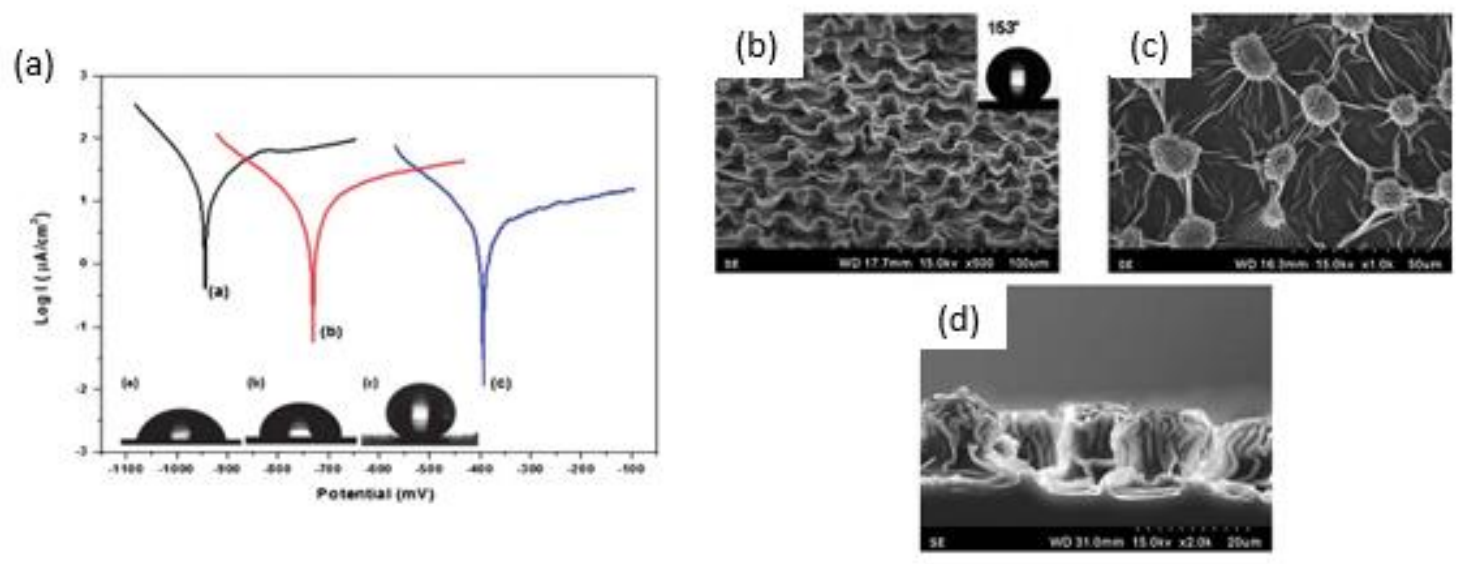

Figure 21: (a) Potentiodynamic polarization curve of the bare coating with smooth surface and coating with superhydrophobic surface of cold rolled steel; (b) the SEM image of the superhydrophobic surface with Xanthosoma sagittifolium leaf-like microstructure; (c) top-view of the surface; (d) side-view of the surface [238].

\section{Summary}

Nature-inspired superhydrophobic surfaces have received enormous attention due to their specific properties and potential industrial applications. Fundamental theories for describing wetting phenomena on superhydrophobic surfaces derive from the work of Young, Wenzel, and CassieBaxter. The combination of surface roughness and low surface energy materials are essential for creating superhydrophobic surfaces.

The corrosion of metals such as aluminum, copper, magnesium, and steel can waste natural resources and degrade infrastructure. Improving the corrosion resistance of these metals is a 
remarkable application of superhydrophobic surfaces. In this review, we summarize the corrosion resistance of superhydrophobic coatings for a range of metal surfaces. Potentiodynamic polarization curves are commonly used to compare the corrosion resistance of different substrates. Studies of corrosion resistant superhydrophobic surfaces highlight a shift of corrosion potential to positive values and a reduction of more than two orders of magnitude of corrosion current density. The reduction of the water contact area and the formation of air barriers diminishes the interaction between such metal surfaces and liquid. This leads to superb corrosion resistance and a lower corrosion rate. Furthermore, long-lasting superhydrophobicity and corrosion resistance of these surfaces hold promise for practical applications in both daily life and industrial needs. As such, research into superhydrophobic surfaces as barriers against the corrosion of metals demands more consideration.

\section{References}

1. Wang, D. and G.P. Bierwagen, Sol-gel coatings on metals for corrosion protection. Progress in organic coatings, 2009. 64(4): p. 327-338.

2. Chatterjee, U., S.K. Bose, and S.K. Roy, Environmental Degradation of Metals: Corrosion Technology Series/142001: CRC Press.

3. Ejenstam, L., et al., The effect of superhydrophobic wetting state on corrosion protection-the AKD example. Journal of colloid and interface science, 2013. 412: p. 56-64.

4. Nguyen, T.N., J.B. Hubbard, and G.B. MCFADDEN, A mathematical model for the cathodic blistering of organic coatings on steel immersed in electrolytes. JCT, Journal of coatings technology, 1991. 63(794): p. 43-52.

5. Metroke, T.L., R.L. Parkhill, and E.T. Knobbe, Passivation of metal alloys using sol-gel-derived materials-a review. Progress in organic coatings, 2001. 41(4): p. 233-238.

6. Cicek, V. and B. Al-Numan, Corrosion Chemistry2011: Wiley.

7. Momen, G. and M. Farzaneh, Facile approach in the development of icephobic hierarchically textured coatings as corrosion barrier. Applied Surface Science, 2014. 299: p. 41-46.

8. Wang, P., D. Zhang, and Z. Lu, Advantage of super-hydrophobic surface as a barrier against atmospheric corrosion induced by salt deliquescence. Corrosion Science, 2015. 90: p. 23-32.

9. Sparks, B.J., et al., Superhydrophobic hybrid inorganic-organic thiol-ene surfaces fabricated via spray-deposition and photopolymerization. ACS applied materials \& interfaces, 2013. 5(5): p. 1811-1817. 
10. Lee, M.W., et al., Electrospun polystyrene nanofiber membrane with superhydrophobicity and superoleophilicity for selective separation of water and low viscous oil. ACS applied materials \& interfaces, 2013. 5(21): p. 10597-10604.

11. Lu, Z., P. Wang, and D. Zhang, Super-hydrophobic film fabricated on aluminium surface as a barrier to atmospheric corrosion in a marine environment. Corrosion Science, 2015. 91: p. 287296.

12. Feng, L., et al., Superhydrophobic aluminum alloy surface: fabrication, structure, and corrosion resistance. Colloids and Surfaces A: Physicochemical and Engineering Aspects, 2014. 441: p. 319325.

13. de Lara, L.R., R. Jagdheesh, and J. Ocaña, Corrosion resistance of laser patterned ultrahydrophobic aluminium surface. Materials Letters, 2016. 184: p. 100-103.

14. Byun, D., et al., Wetting characteristics of insect wing surfaces. Journal of Bionic Engineering, 2009. 6(1): p. 63-70.

15. Zang, D., et al., Stearic acid modified aluminum surfaces with controlled wetting properties and corrosion resistance. Corrosion Science, 2014. 83: p. 86-93.

16. Zhu, J., et al., Nanodome solar cells with efficient light management and self-cleaning. Nano letters, 2009. 10(6): p. 1979-1984.

17. Choi, S.J. and S.Y. Huh, Direct Structuring of a Biomimetic Anti-Reflective, Self-Cleaning Surface for Light Harvesting in Organic Solar Cells. Macromolecular rapid communications, 2010. 31(6): p. 539-544.

18. Fürstner, R., et al., Wetting and self-cleaning properties of artificial superhydrophobic surfaces. Langmuir, 2005. 21(3): p. 956-961.

19. Bhushan, B., Y.C. Jung, and K. Koch, Self-cleaning efficiency of artificial superhydrophobic surfaces. Langmuir, 2009. 25(5): p. 3240-3248.

20. Nakajima, A., et al., Transparent superhydrophobic thin films with self-cleaning properties. Langmuir, 2000. 16(17): p. 7044-7047.

21. Zhao, L., et al., One-step method for the fabrication of superhydrophobic surface on magnesium alloy and its corrosion protection, antifouling performance. Corrosion Science, 2014. 80: p. 177183.

22. Chapman, J. and F. Regan, Nanofunctionalized superhydrophobic antifouling coatings for environmental sensor applications-advancing deployment with answers from nature. Advanced Engineering Materials, 2012. 14(4): p. B175-B184.

23. Xue, C.-H., et al., Fabrication of robust and antifouling superhydrophobic surfaces via surfaceinitiated atom transfer radical polymerization. ACS applied materials \& interfaces, 2015. 7(15): p. 8251-8259.

24. Menini, R., Z. Ghalmi, and M. Farzaneh, Highly resistant icephobic coatings on aluminum alloys. Cold Regions Science and Technology, 2011. 65(1): p. 65-69.

25. Jafari, R., R. Menini, and M. Farzaneh, Superhydrophobic and icephobic surfaces prepared by RFsputtered polytetrafluoroethylene coatings. Applied Surface Science, 2010. 257(5): p. 1540-1543.

26. Crick, C.R., J.A. Gibbins, and I.P. Parkin, Superhydrophobic polymer-coated copper-mesh; membranes for highly efficient oil-water separation. Journal of Materials Chemistry A, 2013. 1(19): p. 5943-5948.

27. Li, K., et al., Facile fabrication of a robust superhydrophobic/superoleophilic sponge for selective oil absorption from oily water. RSC Advances, 2014. 4(45): p. 23861-23868.

28. Bhushan, B. and Y.C. Jung, Natural and biomimetic artificial surfaces for superhydrophobicity, self-cleaning, low adhesion, and drag reduction. Progress in Materials Science, 2011. 56(1): p. 1108. 
29. Daniello, R.J., N.E. Waterhouse, and J.P. Rothstein, Drag reduction in turbulent flows over superhydrophobic surfaces. Physics of Fluids (1994-present), 2009. 21(8): p. 085103.

30. Feng, L., et al., Fabrication of superhydrophobic aluminium alloy surface with excellent corrosion resistance by a facile and environment-friendly method. Applied Surface Science, 2013. 283: p. 367-374.

31. Li, X., et al., Fabrication of superhydrophobic surface with improved corrosion inhibition on 6061 aluminum alloy substrate. Applied Surface Science, 2015. 342: p. 76-83.

32. Liu, T., et al., Super-hydrophobic surfaces improve corrosion resistance of copper in seawater. Electrochimica Acta, 2007. 52(11): p. 3709-3713.

33. Rao, A.V., et al., Mechanically stable and corrosion resistant superhydrophobic sol-gel coatings on copper substrate. Applied Surface Science, 2011. 257(13): p. 5772-5776.

34. Su, F. and K. Yao, Facile fabrication of superhydrophobic surface with excellent mechanical abrasion and corrosion resistance on copper substrate by a novel method. ACS applied materials \& interfaces, 2014. 6(11): p. 8762-8770.

35. Ishizaki, T., et al., Corrosion resistance and chemical stability of super-hydrophobic film deposited on magnesium alloy AZ31 by microwave plasma-enhanced chemical vapor deposition. Electrochimica Acta, 2010. 55(23): p. 7094-7101.

36. Liu, Y., et al., A electro-deposition process for fabrication of biomimetic super-hydrophobic surface and its corrosion resistance on magnesium alloy. Electrochimica Acta, 2014. 125: p. 395403.

37. Wang, S., et al., Preparation of superhydrophobic silica film on $\mathrm{Mg}-\mathrm{Nd}-\mathrm{Zn}-\mathrm{Zr}$ magnesium alloy with enhanced corrosion resistance by combining micro-arc oxidation and sol-gel method. Surface and Coatings Technology, 2012. 213: p. 192-201.

38. Wang, N., et al., Mechanically robust superhydrophobic steel surface with anti-icing, UVdurability, and corrosion resistance properties. ACS applied materials \& interfaces, 2015. 7(11): p. 6260-6272.

39. Wu, L.-K., X.-F. Zhang, and J.-M. Hu, Corrosion protection of mild steel by one-step electrodeposition of superhydrophobic silica film. Corrosion Science, 2014. 85: p. 482-487.

40. Fillion, R., A. Riahi, and A. Edrisy, A review of icing prevention in photovoltaic devices by surface engineering. Renewable and Sustainable Energy Reviews, 2014. 32: p. 797-809.

41. Song, J.-H., et al., Dynamic hydrophobicity of water droplets on the line-patterned hydrophobic surfaces. Surface science, 2006. 600(13): p. 2711-2717.

42. Sahoo, B.N. and B. Kandasubramanian, Recent progress in fabrication and characterisation of hierarchical biomimetic superhydrophobic structures. RSC Advances, 2014. 4(42): p. 2205322093.

43. Krasowska, M., J. Zawala, and K. Malysa, Air at hydrophobic surfaces and kinetics of three phase contact formation. Advances in colloid and interface science, 2009. 147: p. 155-169.

44. Neinhuis, C. and W. Barthlott, Characterization and distribution of water-repellent, self-cleaning plant surfaces. Annals of botany, 1997. 79(6): p. 667-677.

45. Barthlott, W. and C. Neinhuis, Purity of the sacred lotus, or escape from contamination in biological surfaces. Planta, 1997. 202(1): p. 1-8.

46. Feng, L., et al., Petal effect: a superhydrophobic state with high adhesive force. Langmuir, 2008. 24(8): p. 4114-4119.

47. Guo, Z. and W. Liu, Biomimic from the superhydrophobic plant leaves in nature: Binary structure and unitary structure. Plant Science, 2007. 172(6): p. 1103-1112.

48. Gao, X. and L. Jiang, Biophysics: water-repellent legs of water striders. Nature, 2004. 432(7013): p. 36-36. 
49. Sun, T., et al., Bioinspired surfaces with special wettability. Accounts of Chemical Research, 2005. 38(8): p. 644-652.

50. Lee, W., et al., Nanostructuring of a polymeric substrate with well-defined nanometer-scale topography and tailored surface wettability. Langmuir, 2004. 20(18): p. 7665-7669.

51. Zheng, Y., X. Gao, and L. Jiang, Directional adhesion of superhydrophobic butterfly wings. Soft Matter, 2007. 3(2): p. 178-182.

52. Wang, S., et al., Icephobicity of Penguins Spheniscus Humboldti and an Artificial Replica of Penguin Feather with Air-Infused Hierarchical Rough Structures. The Journal of Physical Chemistry C, 2016.

53. Koch, K., B. Bhushan, and W. Barthlott, Diversity of structure, morphology and wetting of plant surfaces. Soft Matter, 2008. 4(10): p. 1943-1963.

54. Fang, Y., et al., Effects of methanol on wettability of the non-smooth surface on butterfly wing. Journal of Bionic Engineering, 2008. 5(2): p. 127-133.

55. Sun, M., et al., Artificial lotus leaf by nanocasting. Langmuir, 2005. 21(19): p. 8978-8981.

56. Yan, Y., N. Gao, and W. Barthlott, Mimicking natural superhydrophobic surfaces and grasping the wetting process: A review on recent progress in preparing superhydrophobic surfaces. Advances in colloid and interface science, 2011. 169(2): p. 80-105.

57. Koch, K., et al., Self assembly of epicuticular waxes on living plant surfaces imaged by atomic force microscopy (AFM). Journal of Experimental Botany, 2004. 55(397): p. 711-718.

58. Guo, Z., W. Liu, and B.-L. Su, Superhydrophobic surfaces: from natural to biomimetic to functional. Journal of colloid and interface science, 2011. 353(2): p. 335-355.

59. Bhushan, B. and E.K. Her, Fabrication of superhydrophobic surfaces with high and low adhesion inspired from rose petal. Langmuir, 2010. 26(11): p. 8207-8217.

60. Gu, Z.-Z., et al., Artificial silver ragwort surface. Applied Physics Letters, 2005. 86(20): p. 201915.

61. Miyauchi, Y., B. Ding, and S. Shiratori, Fabrication of a silver-ragwort-leaf-like super-hydrophobic micro/nanoporous fibrous mat surface by electrospinning. Nanotechnology, 2006. 17(20): p. 5151.

62. Barthlott, W., et al., Classification and terminology of plant epicuticular waxes. Botanical Journal of the Linnean Society, 1998. 126(3): p. 237-260.

63. Young, T., An essay on the cohesion of fluids. Philosophical Transactions of the Royal Society of London, 1805. 95: p. 65-87.

64. Whyman, G., E. Bormashenko, and T. Stein, The rigorous derivation of Young, Cassie-Baxter and Wenzel equations and the analysis of the contact angle hysteresis phenomenon. Chemical Physics Letters, 2008. 450(4): p. 355-359.

65. Gowri, S., et al., Polymer nanocomposites for multifunctional finishing of textiles-a review. Textile Research Journal, 2010. 80(13): p. 1290-1306.

66. Sas, I., et al., Literature review on superhydrophobic self-cleaning surfaces produced by electrospinning. Journal of Polymer Science Part B: Polymer Physics, 2012. 50(12): p. 824-845.

67. Jafari, R., S. Asadollahi, and M. Farzaneh, Applications of plasma technology in development of superhydrophobic surfaces. Plasma Chemistry and Plasma Processing, 2013. 33(1): p. 177-200.

68. Wenzel, R.N., Resistance of solid surfaces to wetting by water. Industrial \& Engineering Chemistry, 1936. 28(8): p. 988-994.

69. Callies, M. and D. Quéré, On water repellency. Soft Matter, 2005. 1(1): p. 55-61.

70. Li, X.-M., D. Reinhoudt, and M. Crego-Calama, What do we need for a superhydrophobic surface? A review on the recent progress in the preparation of superhydrophobic surfaces. Chemical Society Reviews, 2007. 36(8): p. 1350-1368.

71. Quéré, D., Rough ideas on wetting. Physica A: Statistical Mechanics and its Applications, 2002. 313(1): p. 32-46. 
72. Quéré, D., Non-sticking drops. Reports on Progress in Physics, 2005. 68(11): p. 2495.

73. Cassie, A. and S. Baxter, Wettability of porous surfaces. Transactions of the Faraday Society, 1944. 40: p. 546-551.

74. Cassie, A., Contact angles. Discussions of the Faraday Society, 1948. 3: p. 11-16.

75. Marmur, A., Wetting on hydrophobic rough surfaces: to be heterogeneous or not to be? Langmuir, 2003. 19(20): p. 8343-8348.

76. Pilotek, S. and H.K. Schmidt, Wettability of microstructured hydrophobic sol-gel coatings. Journal of sol-gel science and technology, 2003. 26(1): p. 789-792.

77. Zhang, D., et al., Superhydrophobic surfaces for corrosion protection: a review of recent progresses and future directions. Journal of Coatings Technology and Research, 2016. 13(1): p. 11-29.

78. Miwa, M., et al., Effects of the surface roughness on sliding angles of water droplets on superhydrophobic surfaces. Langmuir, 2000. 16(13): p. 5754-5760.

79. Long, C.J., J.F. Schumacher, and A.B. Brennan, Potential for tunable static and dynamic contact angle anisotropy on gradient microscale patterned topographies. Langmuir, 2009. 25(22): p. 12982-12989.

80. Zhang, X., et al., Polyelectrolyte multilayer as matrix for electrochemical deposition of gold clusters: toward super-hydrophobic surface. Journal of the American Chemical Society, 2004. 126(10): p. 3064-3065.

81. Buijnsters, J.G., et al., Surface wettability of macroporous anodized aluminum oxide. ACS applied materials \& interfaces, 2013. 5(8): p. 3224-3233.

82. Liu, C., F. Su, and J. Liang, Facile fabrication of a robust and corrosion resistant superhydrophobic aluminum alloy surface by a novel method. RSC Advances, 2014. 4(98): p. 55556-55564.

83. Jafari, R. and M. Farzaneh, SUPERHYDROPHOBIC AND ANTI-ICING COATINGS ON ALUMINIUM ALLOY SURFACES.

84. Jafari, R. and M. Farzaneh. A simple method to create superhydrophobic aluminium surfaces. in Materials Science Forum. 2012. Trans Tech Publ.

85. Feng, L., et al., Super-hydrophobic surfaces: from natural to artificial. Advanced Materials, 2002. 14(24): p. 1857-1860.

86. He, B., N.A. Patankar, and J. Lee, Multiple equilibrium droplet shapes and design criterion for rough hydrophobic surfaces. Langmuir, 2003. 19(12): p. 4999-5003.

87. Wang, C., et al., Facile approach in fabricating superhydrophobic and superoleophilic surface for water and oil mixture separation. ACS applied materials \& interfaces, 2009. 1(11): p. 2613-2617.

88. Gupta, N., S. Sasikala, and H.C. Barshilia, Corrosion study of superhydrophobic magnesium alloy AZ31 surfaces prepared by wet chemical etching process. Nanoscience and Nanotechnology letters, 2012. 4(8): p. 757-765.

89. Yin, B., et al., Preparation and properties of super-hydrophobic coating on magnesium alloy. Applied Surface Science, 2010. 257(5): p. 1666-1671.

90. Cho, Y.J., et al., Direct growth of cerium oxide nanorods on diverse substrates for superhydrophobicity and corrosion resistance. Applied Surface Science, 2015. 340: p. 96-101.

91. Fan, Y., et al., Preparation of superhydrophobic films on copper substrate for corrosion protection. Surface and Coatings Technology, 2014. 244: p. 1-8.

92. Yao, L., et al., Facile synthesis of superhydrophobic surface of ZnO nanoflakes: chemical coating and UV-induced wettability conversion. Nanoscale research letters, 2012. 7(1): p. 216.

93. Foroughi Mobarakeh, L., R. Jafari, and M. Farzaneh. Superhydrophobic surface elaboration using plasma polymerization of hexamethyldisiloxane (HMDSO). in Advanced Materials Research. 2012. Trans Tech Publ. 
94. Huang, Q., et al., Reduced platelet adhesion and improved corrosion resistance of superhydrophobic TiO 2-nanotube-coated 316L stainless steel. Colloids and Surfaces B: Biointerfaces, 2015. 125: p. 134-141.

95. Xiao, F., et al., Superhydrophobic CuO nanoneedle-covered copper surfaces for anticorrosion. Journal of Materials Chemistry A, 2015. 3(8): p. 4374-4388.

96. Zheng, S., et al., Fabrication of self-cleaning superhydrophobic surface on aluminum alloys with excellent corrosion resistance. Surface and Coatings Technology, 2015. 276: p. 341-348.

97. Zhang, H., et al., Facile and fast fabrication method for mechanically robust superhydrophobic surface on aluminum foil. Microelectronic Engineering, 2015. 141: p. 238-242.

98. Brassard, J.-D., et al., Nano-micro structured superhydrophobic zinc coating on steel for prevention of corrosion and ice adhesion. Journal of colloid and interface science, 2015. 447: $p$. 240-247.

99. de Leon, A.C.C., R.B. Pernites, and R.C. Advincula, Superhydrophobic colloidally textured polythiophene film as superior anticorrosion coating. ACS applied materials \& interfaces, 2012. 4(6): p. 3169-3176.

100. Liu, Y., et al., Corrosion inhibition of biomimetic super-hydrophobic electrodeposition coatings on copper substrate. Corrosion Science, 2015. 94: p. 190-196.

101. Fan, Y., et al., Study on fabrication of the superhydrophobic sol-gel films based on copper wafer and its anti-corrosive properties. Applied Surface Science, 2012. 258(17): p. 6531-6536.

102. Boinovich, L., et al., Corrosion resistance of composite coatings on low-carbon steel containing hydrophobic and superhydrophobic layers in combination with oxide sublayers. Corrosion Science, 2012. 55: p. 238-245.

103. Yang, J., et al., Fabrication of stable, transparent and superhydrophobic nanocomposite films with polystyrene functionalized carbon nanotubes. Applied Surface Science, 2009. 255(22): p. 9244-9247.

104. Davis, A., et al., Superhydrophobic nanocomposite surface topography and ice adhesion. ACS applied materials \& interfaces, 2014. 6(12): p. 9272-9279.

105. Gong, G., et al., A highly durable silica/polyimide superhydrophobic nanocomposite film with excellent thermal stability and abrasion-resistant performance. Journal of Materials Chemistry A, 2015. 3(2): p. 713-718.

106. Jafari, R. and M. Farzaneh, Development a simple method to create the superhydrophobic composite coatings. Journal of Composite Materials, 2013. 47(25): p. 3125-3129.

107. Ogihara, H., et al., Simple method for preparing superhydrophobic paper: spray-deposited hydrophobic silica nanoparticle coatings exhibit high water-repellency and transparency. Langmuir, 2012. 28(10): p. 4605-4608.

108. Li, J., et al., A facile one-step spray-coating process for the fabrication of a superhydrophobic attapulgite coated mesh for use in oil/water separation. RSC Advances, 2015. 5(66): p. 5380253808.

109. Yuan, Z., et al., A novel preparation of polystyrene film with a superhydrophobic surface using a template method. Journal of Physics D: Applied Physics, 2007. 40(11): p. 3485.

110. Sato, O., S. Kubo, and Z.-Z. Gu, Structural color films with lotus effects, superhydrophilicity, and tunable stop-bands. Accounts of Chemical Research, 2008. 42(1): p. 1-10.

111. Cho, W.K. and I.S. Choi, Fabrication of hairy polymeric films inspired by geckos: wetting and high adhesion properties. Advanced Functional Materials, 2008. 18(7): p. 1089-1096.

112. Lee, Y., K.-Y. Ju, and J.-K. Lee, Stable biomimetic superhydrophobic surfaces fabricated by polymer replication method from hierarchically structured surfaces of Al templates. Langmuir, 2010. 26(17): p. 14103-14110. 
113. Peng, C.-W., et al., Nano-casting technique to prepare polyaniline surface with biomimetic superhydrophobic structures for anticorrosion application. Electrochimica Acta, 2013. 95: p. 192199.

114. Qian, B. and Z. Shen, Fabrication of superhydrophobic surfaces by dislocation-selective chemical etching on aluminum, copper, and zinc substrates. Langmuir, 2005. 21(20): p. 9007-9009.

115. Roach, P., N.J. Shirtcliffe, and M.I. Newton, Progess in superhydrophobic surface development. Soft Matter, 2008. 4(2): p. 224-240.

116. Jafari, R., L.F. Mobarakeh, and M. Farzaneh, Water-repellency enhancement of nanostructured plasma-polymerized HMDSO coatings using grey-based taguchi method. Nanoscience and Nanotechnology letters, 2012. 4(3): p. 369-374.

117. Kim, T.-i., D. Tahk, and H.H. Lee, Wettability-controllable super water-and moderately oilrepellent surface fabricated by wet chemical etching. Langmuir, 2009. 25(11): p. 6576-6579.

118. Wang, Q., et al., Fabrication of superhydrophobic surfaces on engineering material surfaces with stearic acid. Applied Surface Science, 2008. 254(7): p. 2009-2012.

119. Latthe, S.S., et al., A mechanically bendable superhydrophobic steel surface with self-cleaning and corrosion-resistant properties. Journal of Materials Chemistry A, 2015. 3(27): p. 1426314271.

120. Liu, L., F. Xu, and L. Ma, Facile fabrication of a superhydrophobic Cu surface via a selective etching of high-energy facets. The Journal of Physical Chemistry C, 2012. 116(35): p. 1872218727.

121. Liu, X. and J. He, One-step hydrothermal creation of hierarchical microstructures toward superhydrophilic and superhydrophobic surfaces. Langmuir, 2009. 25(19): p. 11822-11826.

122. Shi, F., et al., Roselike microstructures formed by direct in situ hydrothermal synthesis: from superhydrophilicity to superhydrophobicity. Chemistry of Materials, 2005. 17(24): p. 6177-6180.

123. Aussillous, P. and D. Quéré, Liquid marbles. Nature, 2001. 411(6840): p. 924-927.

124. Ou, J., et al., Superhydrophobic surfaces on light alloy substrates fabricated by a versatile process and their corrosion protection. ACS applied materials \& interfaces, 2013. 5(8): p. 3101-3107.

125. Darmanin, T., et al., Superhydrophobic surfaces by electrochemical processes. Advanced Materials, 2013. 25(10): p. 1378-1394.

126. Jeong, C. and C.-H. Choi, Single-step direct fabrication of pillar-on-pore hybrid nanostructures in anodizing aluminum for superior superhydrophobic efficiency. ACS applied materials \& interfaces, 2012. 4(2): p. 842-848.

127. Su, F., et al., Rapid fabrication of corrosion resistant and superhydrophobic cobalt coating by a one-step electrodeposition. Journal of The Electrochemical Society, 2013. 160(11): p. D593D599.

128. Khorsand, S., K. Raeissi, and F. Ashrafizadeh, Corrosion resistance and long-term durability of super-hydrophobic nickel film prepared by electrodeposition process. Applied Surface Science, 2014. 305: p. 498-505.

129. Li, W. and Z. Kang, Fabrication of corrosion resistant superhydrophobic surface with self-cleaning property on magnesium alloy and its mechanical stability. Surface and Coatings Technology, 2014. 253: p. 205-213.

130. Liu, Q. and Z. Kang, One-step electrodeposition process to fabricate superhydrophobic surface with improved anticorrosion property on magnesium alloy. Materials Letters, 2014. 137: p. 210213.

131. Nakajima, A., K. Hashimoto, and T. Watanabe, Recent studies on super-hydrophobic films. Monatshefte für Chemie/Chemical Monthly, 2001. 132(1): p. 31-41.

132. Lai, Y., et al., Transparent superhydrophobic/superhydrophilic TiO 2-based coatings for selfcleaning and anti-fogging. Journal of Materials Chemistry, 2012. 22(15): p. 7420-7426. 
133. Wang, Z., et al., In situ growth of hierarchical boehmite on 2024 aluminum alloy surface as superhydrophobic materials. RSC Advances, 2014. 4(28): p. 14708-14714.

134. Wang, P., et al., Green approach to fabrication of a super-hydrophobic film on copper and the consequent corrosion resistance. Corrosion Science, 2014. 80: p. 366-373.

135. Wang, Z., et al., Researching a highly anti-corrosion superhydrophobic film fabricated on AZ91D magnesium alloy and its anti-bacteria adhesion effect. Materials Characterization, 2015. 99: p. 200-209.

136. Mobarakeh, L.F., R. Jafari, and M. Farzaneh, The ice repellency of plasma polymerized hexamethyldisiloxane coating. Applied Surface Science, 2013. 284: p. 459-463.

137. SAITO, H., et al., A study on snow sticking weight to water-repellent coatings. 材料, 1997. 46(12Appendix): p. 216-219.

138. Kako, T., et al., Adhesion and sliding of wet snow on a super-hydrophobic surface with hydrophilic channels. Journal of materials science, 2004. 39(2): p. 547-555.

139. Cao, L., et al., Anti-icing superhydrophobic coatings. Langmuir, 2009. 25(21): p. 12444-12448.

140. Jung, S., et al., Are superhydrophobic surfaces best for icephobicity? Langmuir, 2011. 27(6): p. 3059-3066.

141. Feng, L., et al., A super-hydrophobic and super-oleophilic coating mesh film for the separation of oil and water. Angewandte Chemie International Edition, 2004. 43(15): p. 2012-2014.

142. Li, J., et al., Stable superhydrophobic coatings from thiol-ligand nanocrystals and their application in oil/water separation. Journal of Materials Chemistry, 2012. 22(19): p. 9774-9781.

143. Srinivasan, S., et al., Sustainable drag reduction in turbulent Taylor-Couette flows by depositing sprayable superhydrophobic surfaces. Physical review letters, 2015. 114(1): p. 014501.

144. Scardino, A., et al., Microtopography and antifouling properties of the shell surface of the bivalve molluscs Mytilus galloprovincialis and Pinctada imbricata. Biofouling, 2003. 19(S1): p. 221-230.

145. Schultz, M.P., C.J. Kavanagh, and G.W. Swain, Hydrodynamic forces on barnacles: Implications on detachment from fouling-release surfaces. Biofouling, 1999. 13(4): p. 323-335.

146. Zhang, X., L. Wang, and E. Levänen, Superhydrophobic surfaces for the reduction of bacterial adhesion. RSC Advances, 2013. 3(30): p. 12003-12020.

147. Zielecka, M. and E. Bujnowska, Silicone-containing polymer matrices as protective coatings: Properties and applications. Progress in organic coatings, 2006. 55(2): p. 160-167.

148. Levkin, P.A., F. Svec, and J.M. Fréchet, Porous polymer coatings: a versatile approach to superhydrophobic surfaces. Advanced Functional Materials, 2009. 19(12): p. 1993-1998.

149. Zhang, X., et al., Superhydrophobic surfaces: from structural control to functional application. Journal of Materials Chemistry, 2008. 18(6): p. 621-633.

150. Dorvee, J.R., et al., Manipulation of liquid droplets using amphiphilic, magnetic one-dimensional photonic crystal chaperones. Nature Materials, 2004. 3(12): p. 896-899.

151. Suh, K.Y., M.C. Park, and P. Kim, Capillary force lithography: a versatile tool for structured biomaterials interface towards cell and tissue engineering. Advanced Functional Materials, 2009. 19(17): p. 2699-2712.

152. Ganesh, V.A., et al., A review on self-cleaning coatings. Journal of Materials Chemistry, 2011. 21(41): p. 16304-16322.

153. Momen, G., M. Farzaneh, and R. Jafari, Wettability behaviour of RTV silicone rubber coated on nanostructured aluminium surface. Applied Surface Science, 2011. 257(15): p. 6489-6493.

154. Zhang, P. and F. Lv, A review of the recent advances in superhydrophobic surfaces and the emerging energy-related applications. Energy, 2015. 82: p. 1068-1087.

155. Montemor, M., Functional and smart coatings for corrosion protection: a review of recent advances. Surface and Coatings Technology, 2014. 258: p. 17-37. 
156. Schmitt, G., Global needs for knowledge dissemination, research, and development in materials deterioration and corrosion control. World Corrosion Organization, 2009: p. 3-8.

157. Zhang, T. and D. Tang, Current research status of corrosion resistant coatings. Rec. Pat. Corros. Sci, 2009. 1: p. 1-5.

158. Raja, P.B. and M.G. Sethuraman, Natural products as corrosion inhibitor for metals in corrosive media-a review. Materials Letters, 2008. 62(1): p. 113-116.

159. Huang, Y., Protection of metal and alloy surfaces using corrosion resistance nanostructured superhydrophobic coatings2012: Université du Québec à Chicoutimi.

160. McCafferty, E., Introduction to corrosion science2010: Springer Science \& Business Media.

161. Zhang, X., et al., Facile preparation of hopeite coating on stainless steel by chemical conversion method. Surface and Coatings Technology, 2014. 240: p. 361-364.

162. Song, G.-L., et al., The possibility of forming a sacrificial anode coating for $\mathrm{Mg}$. Corrosion Science, 2014. 87: p. 11-14.

163. Refait, P., et al., Corrosion and cathodic protection of carbon steel in the tidal zone: Products, mechanisms and kinetics. Corrosion Science, 2015. 90: p. 375-382.

164. Dick, P.A., G.H. Knörnschild, and L.F. Dick, Anodising and corrosion resistance of AA 7050 friction stir welds. Corrosion Science, 2017. 114: p. 28-36.

165. Chidambaram, D., C.R. Clayton, and G.P. Halada, Interactions of the components of chromate conversion coating with the constituents of aluminum alloy AA2024-T3. Journal of The Electrochemical Society, 2004. 151(3): p. B151-B159.

166. Mitchon, L.N. and J. White, Growth and analysis of octadecylsiloxane monolayers on al2o3 (0001). Langmuir, 2006. 22(15): p. 6549-6554.

167. Zhang, F., et al., Corrosion resistance of superhydrophobic layered double hydroxide films on aluminum. Angewandte Chemie International Edition, 2008. 47(13): p. 2466-2469.

168. Chen, Y., et al., Fabrication and anti-corrosion property of superhydrophobic hybrid film on copper surface and its formation mechanism. Surface and Interface Analysis, 2009. 41(11): p. 872-877.

169. Farhadi, S., Development of nanostructured coatings for protecting the surface of aluminum alloys against corrosion and ice accretion. 2015.

170. Zhang, Y.-L., et al., Recent developments in superhydrophobic surfaces with unique structural and functional properties. Soft Matter, 2012. 8(44): p. 11217-11231.

171. Wang, Z., et al., Facile and fast fabrication of superhydrophobic surface on magnesium alloy. Applied Surface Science, 2013. 271: p. 182-192.

172. Si, Y. and Z. Guo, Superhydrophobic nanocoatings: from materials to fabrications and to applications. Nanoscale, 2015. 7(14): p. 5922-5946.

173. Wang, N. and D. Xiong, Superhydrophobic membranes on metal substrate and their corrosion protection in different corrosive media. Applied Surface Science, 2014. 305: p. 603-608.

174. Liu, Y., et al., Fabrication of a superhydrophobic graphene surface with excellent mechanical abrasion and corrosion resistance on an aluminum alloy substrate. RSC Advances, 2014. 4(85): p. 45389-45396.

175. Palanivel, R., et al., Effect of tool rotational speed and pin profile on microstructure and tensile strength of dissimilar friction stir welded AA5083-H111 and AA6351-T6 aluminum alloys. Materials \& Design, 2012. 40: p. 7-16.

176. Ohno, H., et al., Unintentional Flow of Alloying Elements in Steel during Recycling of End-of-Life Vehicles. Journal of Industrial Ecology, 2014. 18(2): p. 242-253.

177. Vengatesh, P. and M.A. Kulandainathan, Hierarchically ordered self-lubricating superhydrophobic anodized aluminum surfaces with enhanced corrosion resistance. ACS applied materials \& interfaces, 2015. 7(3): p. 1516-1526. 
178. Sherif, E.-S.M., H.R. Ammar, and K.A. Khalil, Effects of copper and titanium on the corrosion behavior of newly fabricated nanocrystalline aluminum in natural seawater. Applied Surface Science, 2014. 301: p. 142-148.

179. Liu, L., et al., Fabrication of superhydrophobic surface by hierarchical growth of lotus-leaf-like boehmite on aluminum foil. Journal of colloid and interface science, 2011. 358(1): p. 277-283.

180. Trompette, J.-L., et al., Influence of the anion specificity on the electrochemical corrosion of anodized aluminum substrates. Electrochimica Acta, 2010. 55(8): p. 2901-2910.

181. Yin, B., et al., A facile method for fabrication of superhydrophobic coating on aluminum alloy. Surface and Interface Analysis, 2012. 44(4): p. 439-444.

182. Shen, D., et al., Microstructure and corrosion behavior of micro-arc oxidation coating on 6061 aluminum alloy pre-treated by high-temperature oxidation. Applied Surface Science, 2013. 287: p. 451-456.

183. Abdulstaar, M., et al., Corrosion behaviour of Al 1050 severely deformed by rotary swaging. Materials \& Design, 2014. 57: p. 325-329.

184. Liang, J., et al., Facile formation of superhydrophobic silica-based surface on aluminum substrate with tetraethylorthosilicate and viny/triethoxysilane as co-precursor and its corrosion resistant performance in corrosive $\mathrm{NaCl}$ aqueous solution. Surface and Coatings Technology, 2014. 240: p. 145-153.

185. Song, J., W. Xu, and Y. Lu, One-step electrochemical machining of superhydrophobic surfaces on aluminum substrates. Journal of materials science, 2012. 47(1): p. 162-168.

186. Moutarlier, V., et al., Molybdate/sulfuric acid anodising of 2024-aluminium alloy: influence of inhibitor concentration on film growth and on corrosion resistance. Surface and Coatings Technology, 2003. 173(1): p. 87-95.

187. Liu, Y., et al., One-step method for fabrication of biomimetic superhydrophobic surface on aluminum alloy. Colloids and Surfaces A: Physicochemical and Engineering Aspects, 2015. 466: $\mathrm{p}$. 125-131.

188. Peng, S., et al., Highly efficient and large-scale fabrication of superhydrophobic alumina surface with strong stability based on self-congregated alumina nanowires. ACS applied materials \& interfaces, 2014. 6(7): p. 4831-4841.

189. Liu, T., et al., Investigations on reducing microbiologically-influenced corrosion of aluminum by using super-hydrophobic surfaces. Electrochimica Acta, 2010. 55(18): p. 5281-5285.

190. Yin, Y., et al., Structure stability and corrosion inhibition of super-hydrophobic film on aluminum in seawater. Applied Surface Science, 2008. 255(5): p. 2978-2984.

191. He, T., et al., Super-hydrophobic surface treatment as corrosion protection for aluminum in seawater. Corrosion Science, 2009. 51(8): p. 1757-1761.

192. Shi, X., et al., Electrochemical and mechanical properties of superhydrophobic aluminum substrates modified with nano-silica and fluorosilane. Surface and Coatings Technology, 2012. 206(17): p. 3700-3713.

193. Li, P., et al., Preparation of silver-cuprous oxide/stearic acid composite coating with superhydrophobicity on copper substrate and evaluation of its friction-reducing and anticorrosion abilities. Applied Surface Science, 2014. 289: p. 21-26.

194. Nunez, L., et al., Corrosion of copper in seawater and its aerosols in a tropical island. Corrosion Science, 2005. 47(2): p. 461-484.

195. Sherif, E.-S.M., Effects of 2-amino-5-(ethylthio)-1, 3, 4-thiadiazole on copper corrosion as a corrosion inhibitor in 3\% NaCl solutions. Applied Surface Science, 2006. 252(24): p. 8615-8623.

196. Wang, P., et al., Protection of copper corrosion by modification of dodecanethiol self-assembled monolayers prepared in aqueous micellar solution. Electrochimica Acta, 2010. 55(3): p. 878-883. 
197. Babic-Samardzija, K., et al., Inhibitive properties and surface morphology of a group of heterocyclic diazoles as inhibitors for acidic iron corrosion. Langmuir, 2005. 21(26): p. 1218712196.

198. Zhang, D.-q., L.-x. Gao, and G.-d. Zhou, Inhibition of copper corrosion in aerated hydrochloric acid solution by heterocyclic compounds containing a mercapto group. Corrosion Science, 2004. 46(12): p. 3031-3040.

199. Qafsaoui, W., et al., Pitting corrosion of copper in sulphate solutions: inhibitive effect of different triazole derivative inhibitors. Journal of applied electrochemistry, 2001. 31(2): p. 223-231.

200. Sherif, E.-S.M., R. Erasmus, and J. Comins, Corrosion of copper in aerated acidic pickling solutions and its inhibition by 3-amino-1, 2, 4-triazole-5-thiol. Journal of colloid and interface science, 2007. 306(1): p. 96-104.

201. Abelev, E., D. Starosvetsky, and Y. Ein-Eli, Enhanced copper surface protection in aqueous solutions containing short-chain alkanoic acid potassium salts. Langmuir, 2007. 23(22): p. 1128111288.

202. Yuan, S., et al., Superhydrophobic fluoropolymer-modified copper surface via surface graft polymerisation for corrosion protection. Corrosion Science, 2011. 53(9): p. 2738-2747.

203. Alagta, A., et al., Corrosion protection properties of hydroxamic acid self-assembled monolayer on carbon steel. Corrosion Science, 2008. 50(6): p. 1644-1649.

204. Tallman, D.E., et al., Electroactive conducting polymers for corrosion control. Journal of Solid State Electrochemistry, 2002. 6(2): p. 73-84.

205. Liu, Y., et al., Fabrication of biomimetic superhydrophobic surface with controlled adhesion by electrodeposition. Chemical Engineering Journal, 2014. 248: p. 440-447.

206. He, G., et al., Controllable growth of durable superhydrophobic coatings on a copper substrate via electrodeposition. Physical Chemistry Chemical Physics, 2015. 17(16): p. 10871-10880.

207. Huang, Y., D.K. Sarkar, and X.-G. Chen, A one-step process to engineer superhydrophobic copper surfaces. Materials Letters, 2010. 64(24): p. 2722-2724.

208. Wang, P., D. Zhang, and R. Qiu, Liquid/solid contact mode of super-hydrophobic film in aqueous solution and its effect on corrosion resistance. Corrosion Science, 2012. 54: p. 77-84.

209. Chen, Z., L. Hao, and C. Chen, A fast electrodeposition method for fabrication of lanthanum superhydrophobic surface with hierarchical micro-nanostructures. Colloids and Surfaces A: Physicochemical and Engineering Aspects, 2012. 401: p. 1-7.

210. Liu, L., et al., Fabrication of superhydrophobic copper sulfide film for corrosion protection of copper. Surface and Coatings Technology, 2015. 272: p. 221-228.

211. Chu, Q., J. Liang, and J. Hao, Facile fabrication of a robust super-hydrophobic surface on magnesium alloy. Colloids and Surfaces A: Physicochemical and Engineering Aspects, 2014. 443: p. 118-122.

212. Wang, P., et al., Fabricated super-hydrophobic film with potentiostatic electrolysis method on copper for corrosion protection. Electrochimica Acta, 2010. 56(1): p. 517-522.

213. Wang, P., et al., Super-hydrophobic metal-complex film fabricated electrochemically on copper as a barrier to corrosive medium. Corrosion Science, 2014. 83: p. 317-326.

214. Gao, R., et al., Fabrication of superhydrophobic magnesium alloy through the oxidation of hydrogen peroxide. Colloids and Surfaces A: Physicochemical and Engineering Aspects, 2013. 436: p. 906-911.

215. Gnedenkov, S., et al., Formation and electrochemical properties of the superhydrophobic nanocomposite coating on PEO pretreated $\mathrm{Mg}-\mathrm{Mn}$-Ce magnesium alloy. Surface and Coatings Technology, 2013. 232: p. 240-246. 
216. Liang, J., L. Hu, and J. Hao, Characterization of microarc oxidation coatings formed on AM60B magnesium alloy in silicate and phosphate electrolytes. Applied Surface Science, 2007. 253(10): p. 4490-4496.

217. Huang, Y., et al., Corrosion resistance properties of superhydrophobic copper surfaces fabricated by one-step electrochemical modification process. Applied Surface Science, 2013. 282: p. 689694.

218. She, Z., et al., Highly anticorrosion, self-cleaning superhydrophobic Ni-Co surface fabricated on AZ91D magnesium alloy. Surface and Coatings Technology, 2014. 251: p. 7-14.

219. Ishizaki, T., Y. Masuda, and M. Sakamoto, Corrosion resistance and durability of superhydrophobic surface formed on magnesium alloy coated with nanostructured cerium oxide film and fluoroalkylsilane molecules in corrosive NaCl aqueous solution. Langmuir, 2011. 27(8): p. 4780-4788.

220. Wang, Y., et al., Super-hydrophobic surface on pure magnesium substrate by wet chemical method. Applied Surface Science, 2010. 256(12): p. 3837-3840.

221. Zhang, F., et al., Fabrication of the superhydrophobic surface on magnesium alloy and its corrosion resistance. Journal of Materials Science \& Technology, 2015. 31(11): p. 1139-1143.

222. Zhou, M., et al., Insitu grown superhydrophobic Zn-Al layered double hydroxides films on magnesium alloy to improve corrosion properties. Applied Surface Science, 2015. 337: p. 172177.

223. She, Z., et al., Researching the fabrication of anticorrosion superhydrophobic surface on magnesium alloy and its mechanical stability and durability. Chemical Engineering Journal, 2013. 228: p. 415-424.

224. Wang, Z., et al., Low-cost and large-scale fabrication method for an environmentally-friendly superhydrophobic coating on magnesium alloy. Journal of Materials Chemistry, 2012. 22(9): p. 4097-4105.

225. She, Z., et al., Novel method for controllable fabrication of a superhydrophobic CuO surface on AZ91D magnesium alloy. ACS applied materials \& interfaces, 2012. 4(8): p. 4348-4356.

226. Wang, J., et al., Construction of superhydrophobic hydromagnesite films on the Mg alloy. Materials Chemistry and Physics, 2011. 129(1): p. 154-160.

227. Gao, R., et al., Fabrication of fibrous szaibelyite with hierarchical structure superhydrophobic coating on AZ31 magnesium alloy for corrosion protection. Chemical Engineering Journal, 2014. 241: p. 352-359.

228. Isimjan, T.T., T. Wang, and S. Rohani, A novel method to prepare superhydrophobic, UV resistance and anti-corrosion steel surface. Chemical Engineering Journal, 2012. 210: p. 182-187.

229. Yearbook, S.S., World steel association, 2015.

230. Li, L., V. Breedveld, and D.W. Hess, Creation of superhydrophobic stainless steel surfaces by acid treatments and hydrophobic film deposition. ACS applied materials \& interfaces, 2012. 4(9): p. 4549-4556.

231. Zhou, C., et al., Corrosion resistance of novel silane-functional polybenzoxazine coating on steel. Corrosion Science, 2013. 70: p. 145-151.

232. Zakaria, K., et al., Electrochemical and quantum chemical studies on carbon steel corrosion protection in $1 \mathrm{MH} 2 \mathrm{SO} 4$ using new eco-friendly Schiff base metal complexes. Journal of the Taiwan Institute of Chemical Engineers, 2016. 61: p. 316-326.

233. Slepski, P., et al., Simultaneous impedance and volumetric studies and additionally potentiodynamic polarization measurements of molasses as a carbon steel corrosion inhibitor in $1 \mathrm{M}$ hydrochloric acid solution. Construction and Building Materials, 2014. 52: p. 482-487. 
234. Nam, N., et al., The behaviour of praseodymium 4-hydroxycinnamate as an inhibitor for carbon dioxide corrosion and oxygen corrosion of steel in NaCl solutions. Corrosion Science, 2014. 80: p. 128-138.

235. Gupta, R. and N. Birbilis, The influence of nanocrystalline structure and processing route on corrosion of stainless steel: A review. Corrosion Science, 2015. 92: p. 1-15.

236. Zhang, H., et al., The Non-Destructive Test of Steel Corrosion in Reinforced Concrete Bridges Using a Micro-Magnetic Sensor. Sensors, 2016. 16(9): p. 1439.

237. Weng, C.-J., et al., Advanced anticorrosive coatings prepared from the mimicked xanthosoma sagittifolium-leaf-like electroactive epoxy with synergistic effects of superhydrophobicity and redox catalytic capability. Chemistry of Materials, 2011. 23(8): p. 2075-2083.

238. Peng, C.-W., et al., UV-curable nanocasting technique to prepare bio-mimetic super-hydrophobic non-fluorinated polymeric surfaces for advanced anticorrosive coatings. Polymer Chemistry, 2013. 4(4): p. 926-932.

239. Li, J., et al., One-step spray-coating process for the fabrication of colorful superhydrophobic coatings with excellent corrosion resistance. Langmuir, 2015. 31(39): p. 10702-10707.

240. Motlagh, N.V., et al., Durable, superhydrophobic, superoleophobic and corrosion resistant coating on the stainless steel surface using a scalable method. Applied Surface Science, 2013. 283: p. 636-647.

241. Mahalakshmi, P., et al., Enhancing corrosion and biofouling resistance through superhydrophobic surface modification. Current Science(Bangalore), 2011. 101(10): p. 1328-1336.

242. Gnedenkov, S., et al., Electrochemical properties of the superhydrophobic coatings on metals and alloys. Journal of the Taiwan Institute of Chemical Engineers, 2014. 45(6): p. 3075-3080.

243. Xu, N., et al., Corrosion performance of superhydrophobic nickel stearate/nickel hydroxide thin films on aluminum alloy by a simple one-step electrodeposition process. Surface and Coatings Technology, 2016. 302: p. 173-184.

244. Farzaneh, A., S.K. Asl, and M. Hosseini, Evaluation effect of electrodeposition parameters on superhydrophobicity and corrosion performance of nickel coatings. Protection of Metals and Physical Chemistry of Surfaces, 2017. 53(1): p. 88-93.

245. Xiang, T., et al., Effect of current density on wettability and corrosion resistance of superhydrophobic nickel coating deposited on low carbon steel. Materials \& Design, 2017. 114: p. 65-72.

246. Tan, J., et al., Simple Fabrication of Superhydrophobic Nickel Surface on Steel Substrate via Electrodeposition. INTERNATIONAL JOURNAL OF ELECTROCHEMICAL SCIENCE, 2017. 12(1): p. 4049.

247. Ding, S., et al., Fabrication of self-cleaning super-hydrophobic nickel/graphene hybrid film with improved corrosion resistance on mild steel. Materials \& Design, 2017. 117: p. 280-288.

248. Zhao, G., et al., One-step electrodeposition of a self-cleaning and corrosion resistant Ni/WS 2 superhydrophobic surface. RSC Advances, 2016. 6(64): p. 59104-59112.

249. Chang, K.-C., et al., Nanocasting technique to prepare lotus-leaf-like superhydrophobic electroactive polyimide as advanced anticorrosive coatings. ACS applied materials \& interfaces, 2013. 5(4): p. 1460-1467. 